\title{
Single domain antibodies against enteric pathogen virulence factors are active as curli fiber fusions on probiotic $E$. coli Nissle 1917
}

Ilia Gelfat ${ }^{1,2}$, Yousuf Aqeel ${ }^{3}$, Jacqueline M. Tremblay ${ }^{4}$, Justyna J. Jaskiewicz ${ }^{4}$, Anishma Shrestha ${ }^{3}$, James

N. Lee ${ }^{3}$, Shenglan $\mathrm{Hu}^{3}$, Xi Qian 3 , Loranne Magoun ${ }^{3}$, Abhineet Sheoran ${ }^{4}$, Daniela Bedenice ${ }^{4}$, Colter Giem² $^{2}$ Avinash Manjula-Basavannaㄹ, Marcia S. Osburne ${ }^{3}$, Saul Tzipori ${ }^{4}$, Charles B. Shoemaker ${ }^{4}$, John M. Leong ${ }^{3,5}, \&$ Neel S. Joshi ${ }^{2 *}$

${ }^{1}$ John A. Paulson School of Engineering and Applied Sciences, Harvard University, Allston, Massachusetts, United States of America

${ }^{2}$ Department of Chemistry and Chemical Biology, Northeastern University, Boston, Massachusetts, United States of America

${ }^{3}$ Department of Molecular Biology and Microbiology, Tufts University School of Medicine, Boston, Massachusetts, United States of America

${ }^{4}$ Department of Infectious Disease and Global Health, Cummings School of Veterinary Medicine, Tufts University, North Grafton, Massachusetts, United States of America

${ }^{5}$ Stuart B. Levy Center for Integrated Management of Antimicrobial Resistance, Tufts University, Medford, Massachusetts, United States of America

* Corresponding author E-mail: ne.joshi@northeastern.edu 


\section{Abstract}

Enteric microbial pathogens, including Escherichia coli, Shigella and Cryptosporidium species, take a particularly heavy toll in low-income countries and are highly associated with infant mortality. We describe here a means to display anti-infective agents on the surface of a probiotic bacterium. Because of their stability and versatility, VHHs, the variable domains of camelid heavy-chain-only antibodies, have potential as components of novel agents to treat or prevent enteric infectious disease. We isolated and characterized VHHs targeting several enteropathogenic Escherichia.coli (EPEC) virulence factors: flagellin (Fla), which is required for bacterial motility and promotes colonization; both intimin and the translocated intimin receptor (Tir), which together play key roles in attachment to enterocytes; and E. coli secreted protein A (EspA), an essential component of the type III secretion system (T3SS) that is required for virulence. Several VHHs that recognize Fla, intimin, or Tir blocked function in vitro. The probiotic strain E. coli Nissle $1917(\mathrm{EcN})$ produces on the bacterial surface curli fibers, which are the major proteinaceous component of E. coli biofilms. A subset of Fla-, intimin-, or Tir-binding VHHs, as well as VHHs that recognize either a T3SS of another important bacterial pathogen (Shigella flexneri), a soluble bacterial toxin (Shiga toxin or Clostridioides difficile toxin TcdA), or a major surface antigen of an important eucaryotic pathogen (Cryptosporidium parvum) were fused to CsgA, the major curli fiber subunit. Scanning electron micrographs indicated CsgA-VHH fusions were assembled into curli fibers on the EcN surface, and Congo Red binding indicated that these recombinant curli fibers were produced at high levels. Ectopic production of these VHHs conferred on $\mathrm{EcN}$ the cognate binding activity and, in the case of anti-Shiga toxin, was neutralizing. Taken together, these results demonstrate the potential of the curli-based pathogen sequestration strategy described herein and contribute to the development of novel VHH-based gut therapeutics. 


\section{Author Summary}

Enteric pathogens are the causative agents of diarrheal disease - a leading cause of infant morbidity and mortality worldwide. While treatment and prevention options such as drugs or vaccines exist for some pathogens, their efficacy and availability are often limited. New therapeutic strategies are therefore needed, especially inexpensive agents in low-income countries where enteric disease burdens are highest. One promising avenue for novel treatments uses VHHs - highly stable, well-expressed, antibody domains derived from camelid species such as llamas and alpacas. The small size, high stability and simple structure of these antibody fragments enables their streamlined production by bacteria such as E. coli, potentially reducing cost and improving scalability. In this work, we describe the development of VHHs targeting multiple virulence factor proteins of pathogenic E. coli and other leading causes of diarrheal disease. These VHHs provide new tools for the research community and may serve as promising components of agents that prevent or treat pathogen infections. Towards that goal, we engineered a novel system in which the probiotic, mucus-establishing bacterial strain E. coli Nissle $1917(\mathrm{EcN})$ is used to express and display VHHs at high density on its surface. By demonstrating the ability of these engineered EcN to bind to pathogens, we provide a first step toward using such probiotics as a cheap, simple, and effective treatment for enteric pathogen infections. 


\section{Introduction}

Enteric pathogens, which include viruses, bacteria, and eukaryotic microbes, are a major cause of global morbidity and mortality. These pathogens take a particularly heavy toll in low-income countries where diarrheal disease remains a major cause of infant mortality $[1,2]$. Traditional interventions such as antibiotics and vaccines suffer from limited efficacy, distribution and implementation challenges, and the rise of antimicrobial resistance [3]. Virulence factors have been identified for many important enteric microbes, but conventional measures to prevent or treat diarrheal disease based on these factors have proved difficult to develop. Therefore, new therapeutic strategies are needed.

One of the leading causes of infant diarrheal disease and associated mortality in low- and middle-income countries is enteropathogenic Escherichia coli (EPEC) [1, 4-6]. Colonization by EPEC is facilitated by flagella- (Fla-) driven motility that promotes penetration of the mucus layer and association with the intestinal epithelium, where bacteria induce the formation of 'attaching and effacing' (AE) lesions [7, 8]. These lesions, which enable epithelial colonization, are characterized by the effacement of microvilli and the induction of filamentous actin 'pedestals' beneath bacteria closely associated with intestinal epithelial cells $[9,10]$. To generate AE lesions, EPEC utilizes a type III secretion system (T3SS) to translocate the bacterial effector Tir (translocated intimin receptor) into host cells, where it localizes to the plasma membrane and binds to the EPEC surface adhesin intimin. Intimin-mediated clustering of Tir triggers the assembly of filamentous actin beneath bound bacteria. The related pathogen, Shiga toxin-producing enterohemorrhagic E. coli (EHEC), a food-borne pathogen which causes systemic illness in high-income regions such as the U.S. and Europe, generates AE lesions by a similar mechanism [9, 11-13], as do some veterinary pathogens such as rabbit enteropathogenic E. coli (REPEC) and the mouse pathogen Citrobacter rodentium [14-16].

The direct administration of antibodies or antibody fragments has been proposed as a potential treatment for enteric diseases of diverse etiology [17-23]. VHHs, the variable domain of camelid heavy-chain-only 
antibodies (also known as 'nanobodies'), appear particularly well suited for this application [18, 24-28]. Unlike conventional antibodies, VHH antibodies can be efficiently and functionally expressed in E. coli thanks to their small size and single-domain structure. Furthermore, VHHs are effectively expressed as fusion proteins with other VHHs, thus potentially enhancing avidity, increasing specificity, and enabling binding to multiple targets [29]. Fusion with other functional domains also adds further versatility to their use as therapeutic agents. Together, these properties confer the potential to reduce production costs, improve scalability, and enable novel therapeutic applications.

Although VHHs have opened many novel therapeutic avenues, several challenges remain for their implementation as intestinal therapeutics. Despite the inherent stability and robustness of many VHHs [30], the harsh chemical and enzymatic conditions and continuous flow found in the GI tract will likely promote the degradation and clearance of VHHs before they reach their target. The delivery of sufficient, stable, and functional VHHs to the gut environment therefore constitutes a substantial hurdle.

Additionally, producing, purifying, and formulating large amounts of VHHs is likely to be resource- and labor-intensive, effectively limiting the practicality of such approaches, a particularly relevant limitation for implementation in low-income nation where the enteric disease burden is highest.

Engineered living therapeutics are an alternative strategy for localized production and delivery of molecules to the gut. By genetically modifying a suitable nonpathogenic bacterial strain, heterologous proteins of interest can be produced in situ, circumventing the challenges associated with traditional drug delivery strategies [31-33]. The ability to utilize bacteria as a therapeutic agent, bypassing the need for protein purification, can potentially render engineered living therapeutics inexpensive and scalable. $E$. coli Nissle $1917(\mathrm{EcN})$ has emerged in recent years as a leading candidate for such approaches [34, 35]. $\mathrm{EcN}$ has an excellent track record of safety through decades of use as a probiotic, and has also been shown to reduce the severity of ulcerative colitis symptoms [36], as well as interfere with the pathogenicity of several enteric pathogens [37], in part due to its ability to colonize the human gastrointestinal tract $[38,39]$. Transient colonization of humans has also been shown using engineered 
EcN [40]. Notably, EcN and other laboratory E. coli strains can produce VHHs, as demonstrated by numerous studies [41, 42].

Curli fibers are the main proteinaceous components of $E$. coli biofilms. In previous work, we used engineered $\mathrm{EcN}$ to display modified curli fibers in vivo [43]. By fusing heterologous protein domains to $\mathrm{CsgA}$ - the major curli subunit - we were able to construct a cell-anchored mesh of robust amyloid fibers endowed with novel functionalities, ranging from the display of anti-inflammatory peptides [43] to the nucleation of gold nanoparticles [44]. By fusing pathogen surface-binding VHHs to CsgA, we sought to adapt this strategy to enable $\mathrm{EcN}$ to bind enteric pathogens in situ, thereby interfering with their pathogen-host interactions and possibly resulting in pathogen elimination. We call this approach "curlibased pathogen sequestration", drawing an analogy to the polymer sequestrants used to remove excess ions from the gut in chronic kidney disease and a handful of other disorders [45, 46].

Here, we describe the generation and characterization of novel VHHs targeting the Fla, Tir, intimin and EspA antigens of several EPEC, REPEC, EHEC, and Citrobacter strains. We then fused a subset of these VHHs, along with several previously described VHHs that bind virulence factors from other enteric pathogens, to CsgA. By expressing these modified curli fibers in $\mathrm{EcN}$ and testing their function, we demonstrated the efficacy of the curli-based sequestration approach in vitro against several pathogenic $E$. coli virulence factors. Finally, we showed that $\mathrm{EcN}$ producing $\mathrm{CsgA}-\mathrm{VHH}$ fusions are capable of recognizing surface antigens on two other major enteric pathogens, Shigella flexneri and the eukaryotic pathogen Cryptosporidium parvum. 


\section{Results}

\section{Generation and initial characterization of VHHs that recognize Fla, Tir, intimin, or EspA}

With the goal of obtaining VHHs that bind to selected virulence factors of AE members of the pathogenic E. coli family (Figure 1), we immunized alpacas with these virulence factor antigens, either purified from selected enteric pathogens or prepared as recombinant proteins. For anti-flagella VHHs, we immunized with both purified REPEC or EPEC flagella or purified recombinant FliC proteins from multiple pathogenic E. coli species. Recombinant REPEC EspA, EHEC and C. rodentium intimins, and EHEC Tir protein were also employed as additional virulence factor immunogens. Unlike flagella, the EspA, intimin, and Tir proteins are relatively well conserved, increasing the likelihood of identifying VHHs that recognize diverse AE pathogens. Following immunization, phage-displayed VHHs prepared from the alpaca B cells were panned and then screened for binding to the immunizing antigens and to orthologous antigens from related AE pathogens as described in Materials and Methods. VHH DNA sequences were then determined, and one or two representative VHHs from each different VHH family (i.e., a family constitutes those VHHs apparently derived from a common B cell progenitor) were selected for soluble protein expression. The selected VHHs and their binding properties are summarized in Table 1. Enzyme-linked immunosorbent assays (ELISAs) were used to estimate the apparent affinity ( $\mathrm{EC}_{50}$ value) of the VHHs for their original antigen, as well as their apparent affinity for homologous targets from other AE pathogens. VHHs varied widely with regard to their binding capacities and cross-specificities (Table 1, Figure S1). Note that some of the selected VHHs were assigned a simplified name related to their target antigen, e.g., " $\alpha$ Int-12" (i.e., “anti-intimin 12”). 


\section{Pathogenic Virulence Factors}

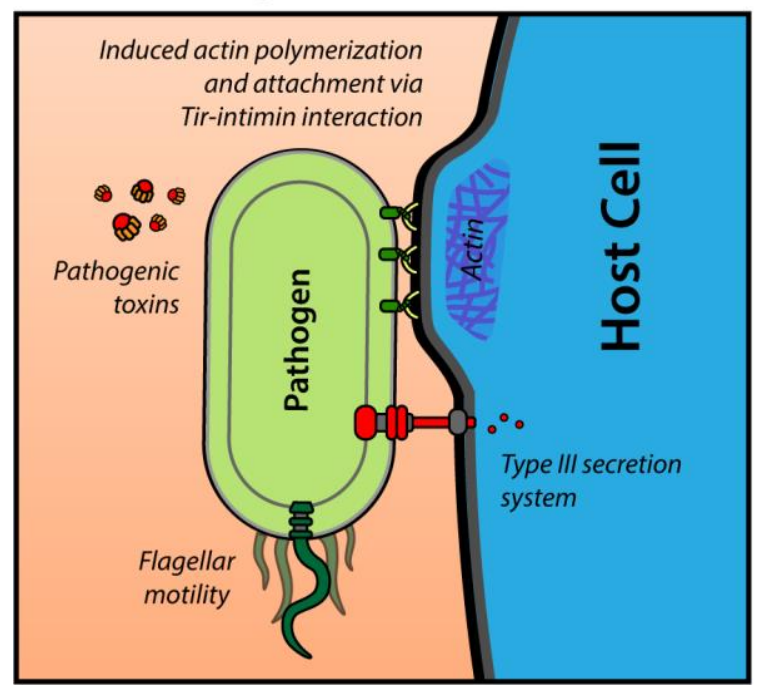

Inhibition by Soluble VHHs

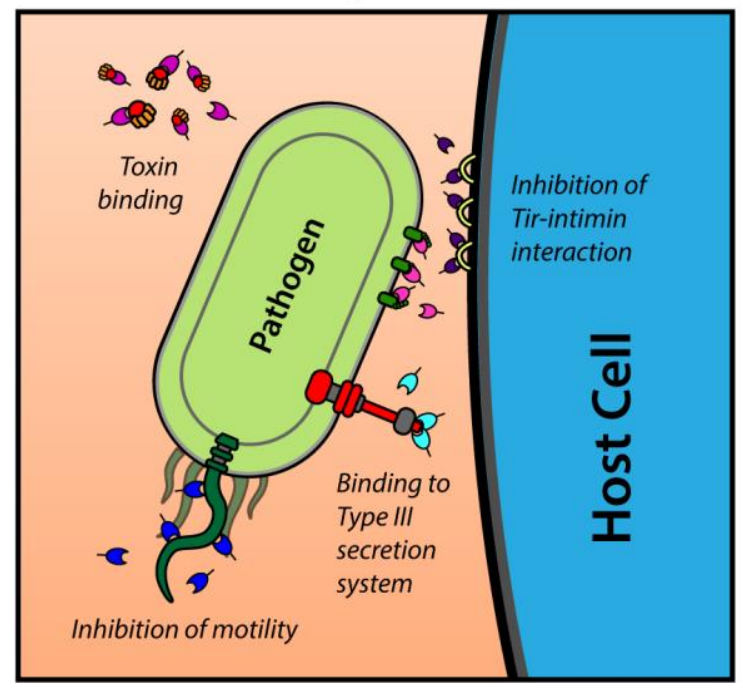

Figure 1: Schematic overview of bacterial virulence factors used as VHH targets in this study.

Despite our success in identifying several VHHs that recognized purified intimin proteins from various pathogenic E. coli, each was highly specific to intimin from only one species (not shown), and, importantly, none recognized E. coli strain MC1061 expressing EPEC or EHEC intimin on the bacterial surface (e.g., $\alpha$ Int-13, Table 1). Since VHHs are particularly dependent on conformational epitopes [47], we hypothesized that, when coated onto plastic wells, recombinant intimins may not always mimic the conformation of intimin as displayed by E. coli $[48,49]$, in spite of demonstrated function in other assays [50]. To test this idea, we used E. coli K12 strain MC1061 expressing EHEC or EPEC intimin as an antigen to select and identify phage-displayed VHHs that recognize bacterial surface intimins. Using this process, we discovered VHHs $\alpha$ Int-12, -14 and -17, which recognized both EPEC and EHEC intimin expressed on the surface of strain MC1061, but did not recognize non-intimin producing MC1061 or recombinant intimin (Table 1, Figure S1). These data highlight the importance of using conformationally native antigens in preference to recombinant proteins for identifying VHHs of interest. 
bioRxiv preprint doi: https://doi.org/10.1101/2021.06.18.448998; this version posted June 18 , 2021. The copyright holder for this preprint (which was not certified by peer review) is the author/funder, who has granted bioRxiv a license to display the preprint in perpetuity. It is made available under aCC-BY-NC 4.0 International license.

Table 1: Selected VHHs

\begin{tabular}{|c|c|c|c|c|c|c|c|c|}
\hline \multicolumn{9}{|c|}{ (a) Anti-Fla VHHs } \\
\hline \multirow{2}{*}{$\begin{array}{l}\text { VHH } \\
\text { name }\end{array}$} & \multirow{2}{*}{$\begin{array}{l}\text { Vector } \\
\text { name }\end{array}$} & \multirow{2}{*}{$\begin{array}{l}\text { Simplified } \\
\text { name }\end{array}$} & \multirow{2}{*}{ Immunogen } & \multirow[b]{2}{*}{ Panned on } & \multicolumn{3}{|c|}{$\mathbf{E C}_{50}{ }^{\text {a }}$} & \multirow{2}{*}{$\begin{array}{c}\text { REPEC } \\
\text { motility } \\
\text { inhibition }\end{array}$} \\
\hline & & & & & $\begin{array}{l}\text { REPEC } \\
\text { flagella }\end{array}$ & $\begin{array}{c}\text { EPEC } \\
\text { flagella }\end{array}$ & $\begin{array}{c}\text { EPEC } \\
\text { FliC }\end{array}$ & \\
\hline JUV-B11 & JVE-2 & $\alpha$ Fla-1 & \multirow{8}{*}{$\begin{array}{c}\text { REPEC } \\
\text { flagella; } \\
\text { EPEC rFliC }\end{array}$} & \multirow{6}{*}{ REPEC flagella } & Trace $^{b}$ & NB & Trace & - \\
\hline JUV-C4 & JVE-4 & $\alpha$ Fla-2 & & & 0.5 & 1 & 0.3 & ND \\
\hline JUV-E8 & JVE-5 & $\alpha$ Fla-3 & & & 0.5 & Trace & NB & + \\
\hline JUV-G8 & JVE-7 & $\alpha$ Fla-4 & & & 5 & NB & 10 & + \\
\hline JUV-H1 & JVE-10 & $\alpha$ Fla-5 & & & NB & NB & NB & - \\
\hline JUV-H5 & JVE-11 & $\alpha$ Fla-6 & & & 5 & NB & 25 & + \\
\hline JWU-F3 & JXA-1 & & & \multirow{2}{*}{$\begin{array}{l}\text { MC1061/EPEC } \\
\text { intimin }\end{array}$} & 10 & 0.2 & ND & ND \\
\hline JWU-H4 & JXA-5 & & & & 3 & 10 & ND & ND \\
\hline JXE-B1 & JXK-1 & & $\begin{array}{c}\text { EPEC } \\
\text { flagella }\end{array}$ & EPEC flagella & NB & 0.1 & ND & ND \\
\hline
\end{tabular}

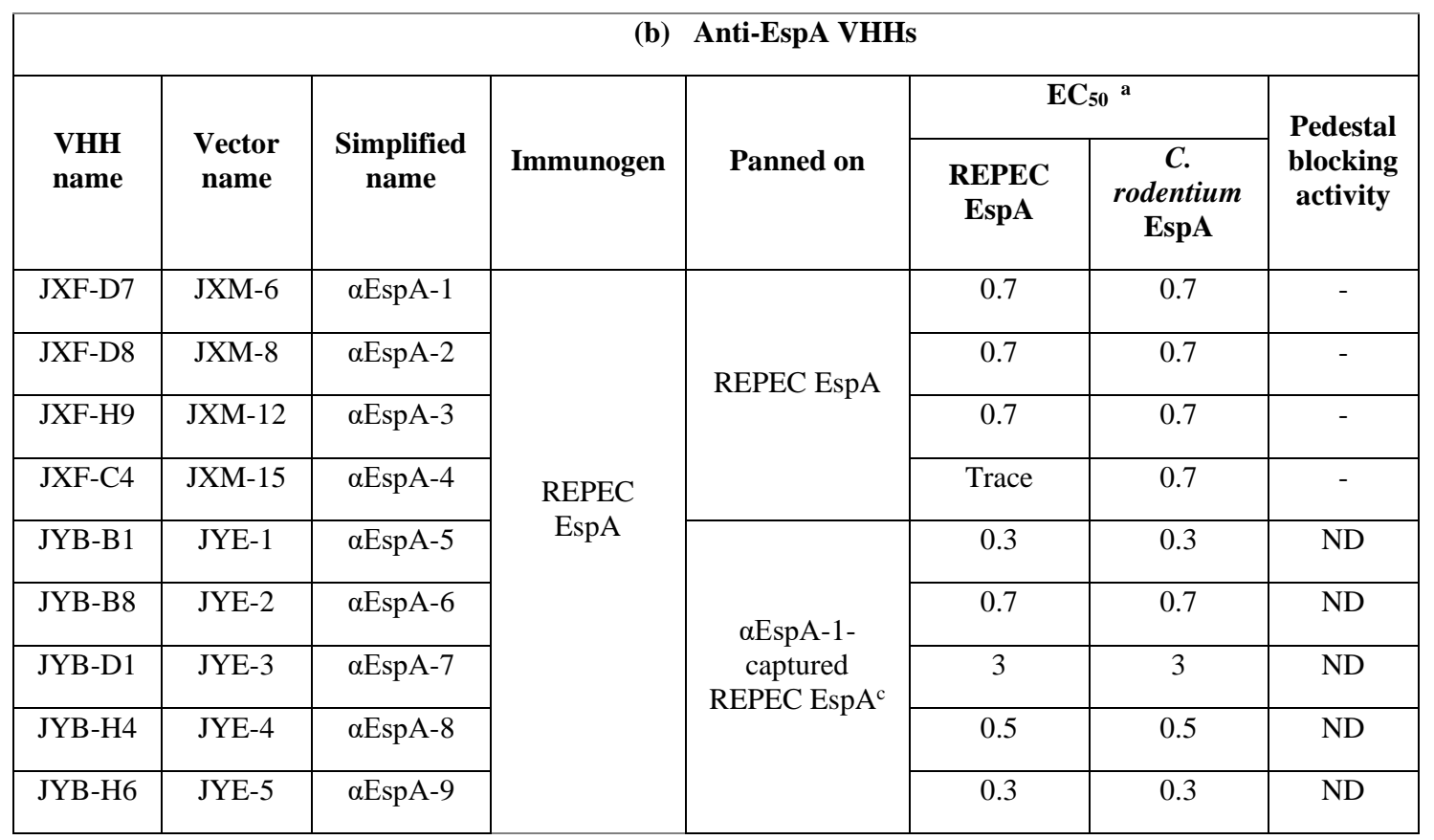


bioRxiv preprint doi: https://doi.org/10.1101/2021.06.18.448998; this version posted June 18, 2021. The copyright holder for this preprint (which was not certified by peer review) is the author/funder, who has granted bioRxiv a license to display the preprint in perpetuity. It is made available under aCC-BY-NC 4.0 International license.

\begin{tabular}{|c|c|c|c|c|c|c|c|c|}
\hline & & & (c) $A$ & ti-Tir VI & & & & \\
\hline \multirow{2}{*}{$\begin{array}{l}\text { VHH } \\
\text { name }\end{array}$} & \multirow{2}{*}{$\begin{array}{l}\text { Vector } \\
\text { name }\end{array}$} & \multirow{2}{*}{$\begin{array}{c}\text { Simplified } \\
\text { name }\end{array}$} & \multirow{2}{*}{ Immunogen } & \multirow{2}{*}{$\begin{array}{c}\text { Panned } \\
\text { on }\end{array}$} & \multicolumn{3}{|c|}{$\mathrm{EC}_{50}{ }^{\mathrm{a}}$} & \multirow{2}{*}{$\begin{array}{c}\text { Tir-intimin } \\
\text { blocking } \\
\text { activity }^{d}\end{array}$} \\
\hline & & & & & $\begin{array}{c}\text { EHEC } \\
\text { Tir }\end{array}$ & $\begin{array}{c}\text { EPEC } \\
\text { Tir }\end{array}$ & $\begin{array}{c}\text { REPEC } \\
\text { Tir }\end{array}$ & \\
\hline JVB-C6 & JVG-1 & $\alpha$ Tir-1 & \multirow{14}{*}{ EHEC Tir } & \multirow{3}{*}{$\begin{array}{c}\text { REPEC } \\
\text { Tir }\end{array}$} & trace & 50 & trace & - \\
\hline JVB-G4 & JVG-2 & $\alpha \operatorname{Tir}-2$ & & & 0.1 & 0.1 & 0.1 & $++^{e}$ \\
\hline JVB-G8 & JVG-3 & $\alpha \operatorname{Tir}-3$ & & & 0.2 & 0.2 & 0.2 & - \\
\hline JVC-C6 & JVI-1 & $\alpha$ Tir-4 & & \multirow{11}{*}{$\begin{array}{c}\text { EHEC } \\
\text { Tir }\end{array}$} & 0.1 & 0.2 & 0.1 & + \\
\hline JVC-D10 & JVI-2 & $\alpha \operatorname{Tir}-5$ & & & 0.1 & 0.2 & 0.2 & - \\
\hline JVC-E5 & JVI-3 & $\alpha$ Tir-6 & & & 0.1 & 0.2 & 0.2 & + \\
\hline JVA-A1 & JVF-1 & $\alpha \operatorname{Tir}-7$ & & & 0.7 & 10 & 3 & - \\
\hline JVA-C8 & JVF-2 & $\alpha \operatorname{Tir}-8$ & & & 0.1 & 0.2 & 0.2 & +++ \\
\hline JVA-C9 & JVF-3 & $\alpha$ Tir-9 & & & 0.1 & 5 & 0.2 & - \\
\hline JVA-D4 & JVF-4 & $\alpha \operatorname{Tir}-10$ & & & 0.5 & 0.5 & 0.5 & - \\
\hline JVA-F6 & JVF-7 & $\alpha$ Tir-11 & & & 0.1 & 25 & 0.2 & - \\
\hline JVA-D11 & JVF-8 & $\alpha \operatorname{Tir}-12$ & & & 0.2 & 0.2 & 0.2 & + \\
\hline JVA-E10 & JVF-12 & $\alpha \operatorname{Tir}-13$ & & & 0.5 & 0.2 & 0.1 & - \\
\hline JVA-G1 & JVF-14 & $\alpha \operatorname{Tir}-14$ & & & 0.1 & 0.2 & 0.2 & +++ \\
\hline
\end{tabular}

\begin{tabular}{|c|c|c|c|c|c|c|c|c|}
\hline & & & & Anti-intimin V & & & & \\
\hline \multirow[b]{2}{*}{$\begin{array}{c}\text { VHH } \\
\text { name }\end{array}$} & \multirow[b]{2}{*}{$\begin{array}{l}\text { Vector } \\
\text { name }\end{array}$} & \multirow[b]{2}{*}{$\begin{array}{c}\text { Simplified } \\
\text { name }\end{array}$} & \multirow[b]{2}{*}{ Immunogen } & \multirow[b]{2}{*}{ Panned on } & \multicolumn{3}{|c|}{$\mathrm{EC}_{50}{ }^{\text {a }}$} & \multirow{2}{*}{$\begin{array}{l}\text { Pedestal } \\
\text { blocking } \\
\text { activity }\end{array}$} \\
\hline & & & & & $\begin{array}{c}\text { EHEC } \\
\text { intimin }\end{array}$ & $\begin{array}{c}\text { EPEC } \\
\text { intimin }\end{array}$ & $\begin{array}{c}\text { MC1061 } \\
\text { /EPEC } \\
\text { intimin }\end{array}$ & \\
\hline JWS-H4 & JWZ-5 & $\alpha \operatorname{Int}-12$ & \multirow{4}{*}{ EHEC intimin } & \multirow{2}{*}{$\begin{array}{c}\text { E. coli } \\
\text { 1061/pInt } \\
\text { (EHEC) }\end{array}$} & Trace & Trace & 10 & - \\
\hline JWT-C1 & JWZ-7 & $\alpha$ Int-13 & & & 0.5 & Trace & NB & + \\
\hline JWU-D8 & JWZ-9 & $\alpha \operatorname{Int}-14$ & & \multirow{2}{*}{$\begin{array}{c}\text { E. coli } \\
\text { 1061/pInt } \\
\text { (EPEC) }\end{array}$} & Trace & Trace & 0.5 & + \\
\hline JWU-G8 & $\begin{array}{c}\text { JWZ- } \\
15\end{array}$ & $\alpha \operatorname{Int}-17$ & & & NB & NB & 0.5 & + \\
\hline $\mathrm{JXN}-\mathrm{E} 2^{\mathrm{e}}$ & JXS-2 & & $\begin{array}{l}\text { C. rodentium } \\
\text { intimin }\end{array}$ & $\begin{array}{c}\text { DH5 } \alpha / \text { pInt }(C . \\
\text { rodentium })\end{array}$ & NB & NB & NB & ND \\
\hline
\end{tabular}

${ }^{\mathrm{a}} \mathrm{EC}_{50}$ estimates based on dilution ELISAs such as shown in Figure S1

${ }^{\mathrm{b}}$ Trace $-\mathrm{EC}_{50}>125 \mathrm{nM}$, i.e., poor but detectable

c Panning employed JXF-D7-captured REPEC EspA target

${ }^{d}$ Tir-intimin binding inhibition from Figure $2:+p<0.01 ;++p<0.001 ;+++p<0.0001$

${ }^{\mathrm{e}} \alpha$ Tir-2 also displayed pedestal blocking activity, Figure 2

${ }^{\mathrm{f}}$ Pedestal blocking activity from Figure 2

${ }^{\mathrm{g}} \mathrm{JXN}-\mathrm{E} 2$ binds to $C$. rodentium intimin with $\mathrm{EC}_{50} \sim 0.5 \mathrm{nM}$, not shown

$\mathrm{NB}$ - no binding; ND - not done 


\section{Anti-Fla VHHs inhibit REPEC motility}

Flagellin (FliC) is the major protein of flagella, which are required for motility and colonization of some pathogenic E. coli [51]. We found that REPEC bacteria were highly motile when applied onto low percentage agar plates (Figure 2a). We therefore utilized this strain to test whether various anti-Fla VHHs could impair motility. REPEC was grown to mid-log phase and incubated with either PBS or different concentrations of VHHs (as described in Materials and Methods). After depositing bacteria onto the center of an agar plate, plates were incubated at room temperature for $24 \mathrm{~h}$ and REPEC motility was then assessed by measuring the bacterial growth diameter. Figure 2a shows that $\alpha$ Fla-1 VHH did not inhibit motility, whereas motility was inhibited by $\alpha$ Fla-6. Two other Fla VHHs, $\alpha$ Fla-3 and 4 also showed marked inhibition of REPEC motility at 6.1 and $2.4 \mu \mathrm{M}$ concentrations (Figure $2 \mathrm{~b}$ ), with an $\mathrm{IC}_{50}$ as low as $1.0 \mu \mathrm{M}$ (Table 1), whereas $\alpha$ Fla-5 showed no motility inhibition, even at $6.1 \mu \mathrm{M}$ (Figure $2 \mathrm{~b}$ ). 
(a)
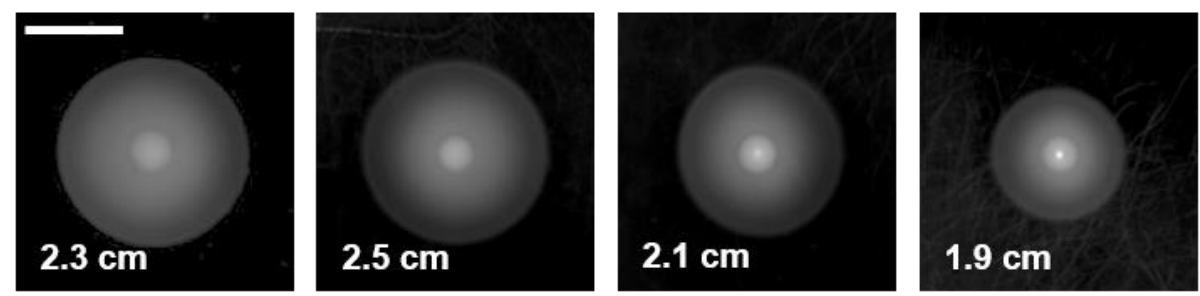

\section{aFla-1}
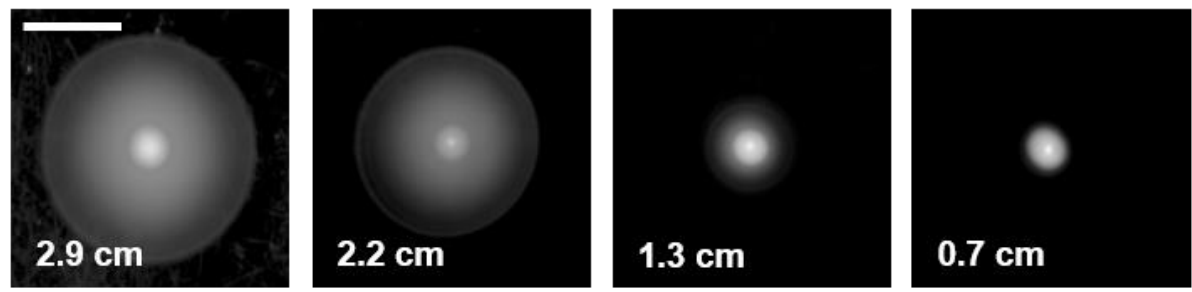

aFla-6

0

0.4

2.4

6.1

\section{VHH concentration $[\mu \mathrm{M}]$}

(b)

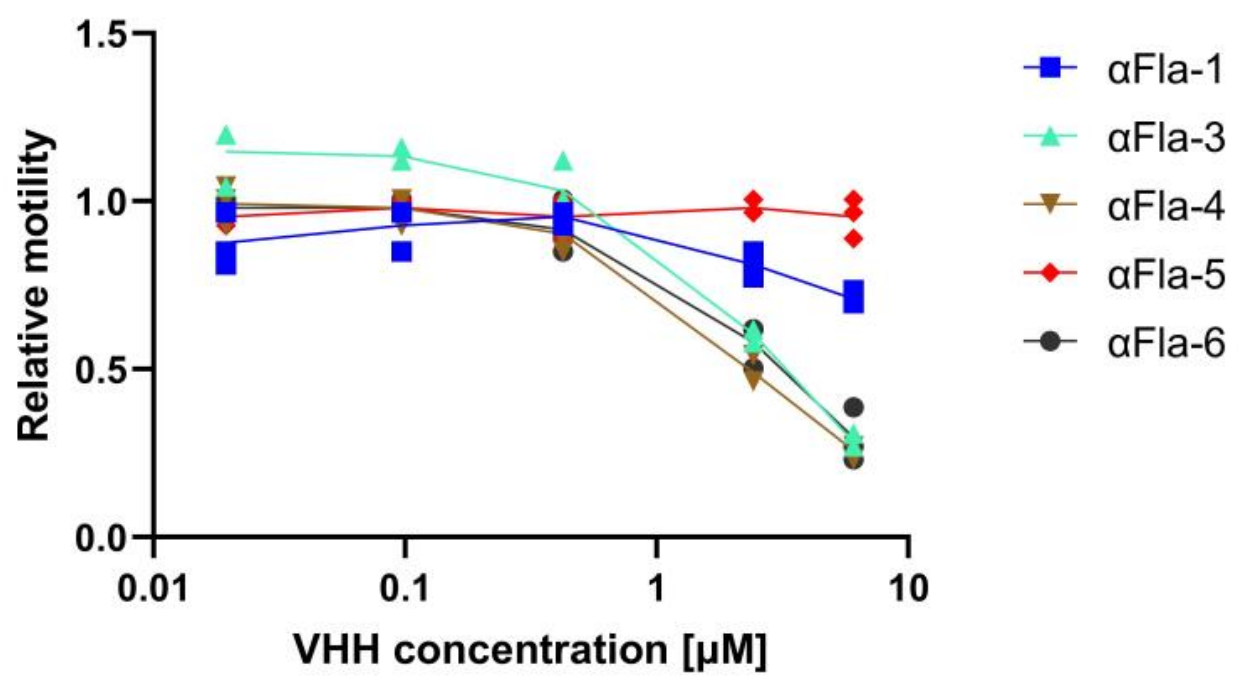

Figure 2: Anti-Fla VHHs can inhibit REPEC motility. (a) Representative images of REPEC growth on motility plates after incubation with varying VHH concentrations with spread diameter indicated (scale bar $=1 \mathrm{~cm})$. (b) Relative motility as a function of $\alpha$ Fla VHH concentration. Spread diameters were normalized to a "no VHH" control.

Specific anti-Tir and anti-intimin VHHs block the interaction between intimin and Tir

The interaction between intimin and Tir is required for bacterial infection of the host. To determine if anti-Tir VHHs can block this interaction, ELISA-based assays were performed. Plates were coated with 
GST-tagged EPEC Tir, then incubated with VHHs or (as a negative control) $0.1 \%$ BSA. Wells were incubated with either GST-tagged EPEC intimin, or with GST alone (as a negative control), and bound GST or GST-intimin was detected with anti-GST antibody. As shown in Figure 3a, 0.1\% BSA showed no ability to block the intimin-Tir interaction, whereas six out of fourteen anti-Tir VHHs showed significant neutralization activity, with $\alpha$ Tir-2, $\alpha$ Tir- 8 and $\alpha$ Tir-14 displaying the most potent activity. Thus, despite high affinity for soluble Tir, many anti-Tir VHHs were ineffective in blocking the interaction between purified Tir and intimin in vitro.

\section{EPEC pedestal formation is inhibited by anti-Tir and anti-intimin VHHs}

During EPEC infection, bacterial Tir protein on host cells binds to intimin on the bacterial surface. This clustering promotes F-actin assembly beneath bacteria bound at the host plasma membrane and results in the formation of actin pedestals that facilitate pathogen colonization. As $\alpha$ Tir-2 was shown to block the intimin-Tir interaction in an ELISA-based assay, we tested whether it was also able to inhibit EPEC pedestal formation. HeLa cells were incubated with EPEC and $100 \mathrm{nM} \alpha \mathrm{Tir}-2 \mathrm{VHH}$ for $3 \mathrm{~h}$ at $37^{\circ} \mathrm{C}$, then stained with DAPI (to stain cell nuclei) and phalloidin (to stain F-actin). Coded images of each sample were scored blindly on a scale of 1 to 5 (see Materials and Methods), where a score of 5 indicates many pedestals. As expected, EPEC infection in the absence of any VHH resulted in robust pedestal formation (Figure 3b), as did the addition of a negative control VHH ( $\alpha$ Fla-2) (Figure 3c). These two controls each yielded a pedestal score of 5. However, $20 \mathrm{nM} \alpha$ Tir-2 partially inhibited pedestal formation (Figure $3 \mathrm{~d}$ ), and $100 \mathrm{nM} \alpha$ Tir-2 completely inhibited EPEC pedestal formation, with no observable pedestals, (Figure 3e). Thus, $\alpha$ Tir- 2 was shown to inhibit in vitro both the interaction between recombinant Tir and intimin, and EPEC pedestal formation, which is triggered by the interaction of these two virulence factors.

Anti-intimin VHHs were also tested for the ability to inhibit EPEC pedestal formation. While $\alpha$ Int-12 showed no inhibition of pedestal formation (Figures 3f and 3g), aInt-13 and -14 both displayed inhibitory 
activity (Figures $3 \mathrm{~h}$ and $3 \mathrm{i}$ ). In addition, $\alpha$ Int-17, which is closely related to $\alpha$ Int-14, also showed potent inhibitory effects, although unblinded scoring was not performed with this VHH (Table 1, data not shown).

Finally, we tested the ability of $\alpha$ EspA-1, 2, 3, and 4 to block pedestal formation ( $\alpha$ EspA-1, 2 and 3 are closely related). Despite their high-affinity binding, none of these anti-EspA VHHs were able to inhibit pedestal formation (Figure S2). However, a panel of anti-EspA VHHs recognizing a different, noncompeting epitope were later isolated by panning the library on $\alpha$ EspA-1 VHH-captured EspA (Table 1, Table S2, VHHs of the JYB series). This new panel will be tested for neutralization of pedestal formation in the future. 

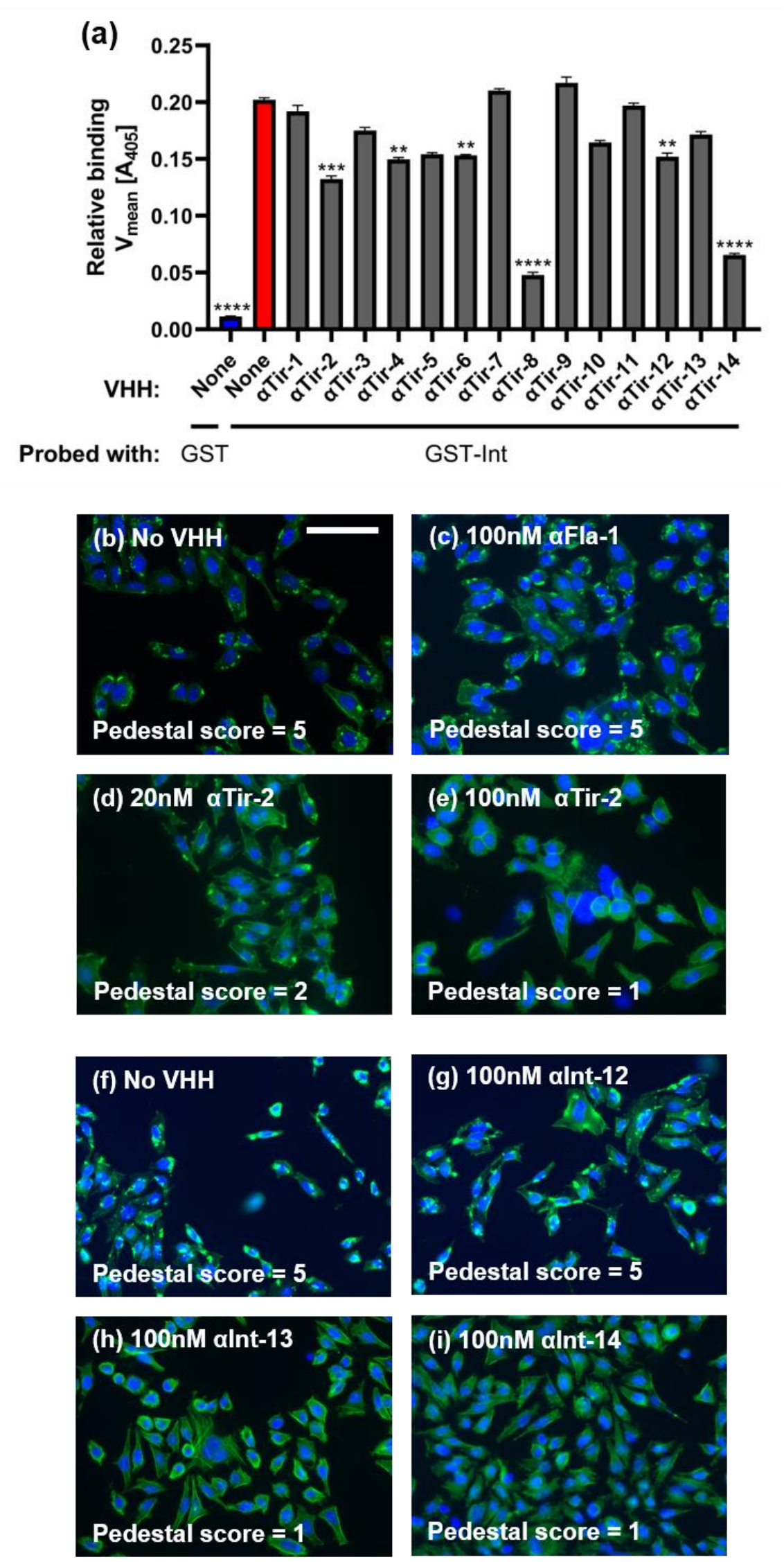
Figure 3: Anti-Tir and anti-intimin VHHs interfere with Tir-intimin binding and pedestal formation. (a) Several anti-Tir VHHs blocked Tir-intimin binding. Data presented as mean \pm SEM. P-values calculated by one-way ANOVA. ** P $<0.01 ; * * *$ $\mathrm{P}<0.001, * * * * \mathrm{P}<0.0001$. (b-i) Anti-Tir and anti-intimin VHHs can inhibit EPEC-mediated pedestal formation $($ scale bar $=100$ $\mu \mathrm{m})$. HeLa cells were exposed to EPEC incubated with VHH, fixed and stained with DAPI (blue) and Alexa Fluor-488 Phalloidin (green). Blinded pedestal scores were assigned by a separate researcher.

\section{Design and expression of curli-VHH fusions in EcN}

Next, we chose 12 anti-enteric pathogen VHHs with which to construct CsgA fusions and test the functional display of various CsgA-VHH amyloid polymers on EcN curli fibers. The VHHs we selected included several anti-virulence VHHs described above as well as VHHs neutralizing enteric toxins TcdA or Stx2, and VHHs binding Shigella or Cryptosporidium surface antigens (Table 2). The CsgA and VHH coding sequences were fused in-frame and inserted into expression plasmid pL6FO, in which a synthetic version of the full curli operon $(\operatorname{csg} B A C E F G)$ was placed under control of an inducible promoter (Figure 4b). The two protein domains were connected by a 14 amino acid glycine-serine linker, and a $6 x H i s-t a g$ was appended to the C-terminus of the VHH domain to facilitate detection. To eliminate potential confounding effects of native CsgA, the plasmids were introduced into EcN strain PBP8, in which the native curli operon was deleted from the genome [43, 52].

Following transformation and induction, curli expression and fiber formation were assessed by a Congo Red binding assay, which detects curli on the surface of bacteria $[44,53]$. Although the degree of Congo Red binding varied slightly between different VHH fusions, overall signal remained high compared to the negative control condition, i.e., plasmid-free strain PBP8 containing neither the wild-type $\operatorname{csg} A$ gene nor any curli fusion (Figure 4e). This result therefore indicates the formation of cell-anchored amyloid fibers on the CsgA-VHH-expressing strains. To further characterize the fusion proteins, field emission scanning electron microscopy images of CsgA-VHH fibers were captured. All CsgA-VHH constructs tested resulted in the formation of curli material (Figure 4d, Figure S3). 
bioRxiv preprint doi: https://doi.org/10.1101/2021.06.18.448998; this version posted June 18, 2021. The copyright holder for this preprint (which was not certified by peer review) is the author/funder, who has granted bioRxiv a license to display the preprint in perpetuity. It is made available under aCC-BY-NC 4.0 International license.

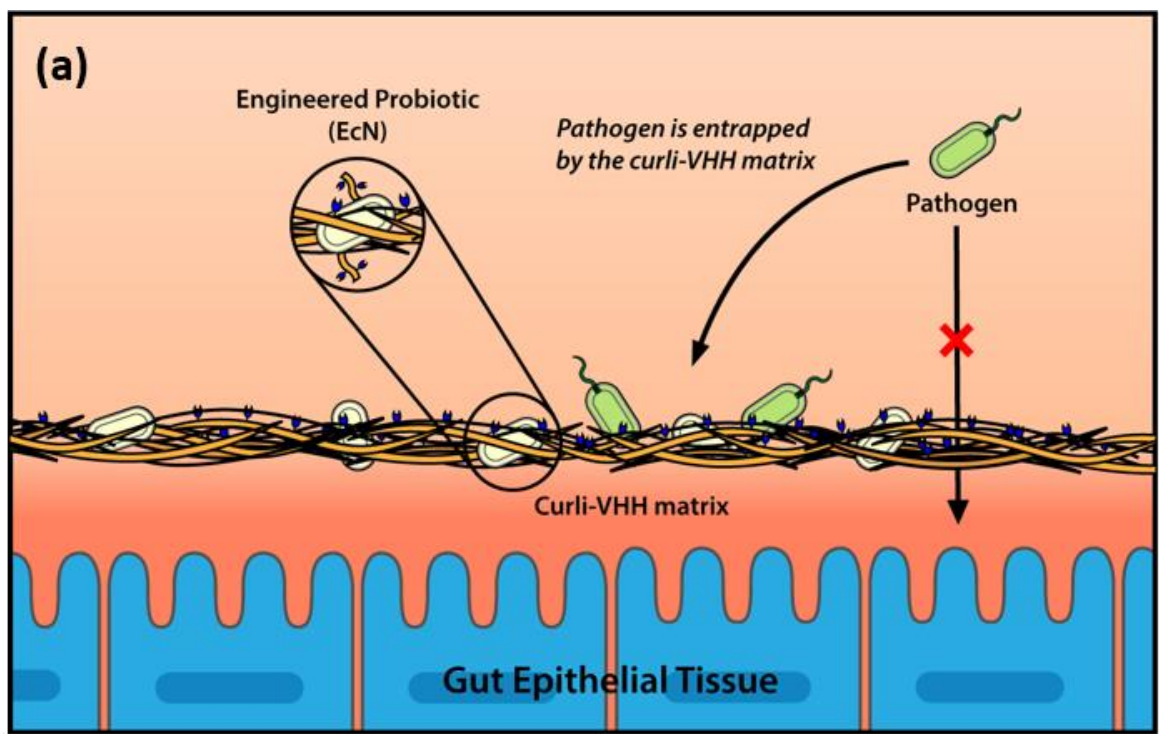

(b)

Plasmid Encoding

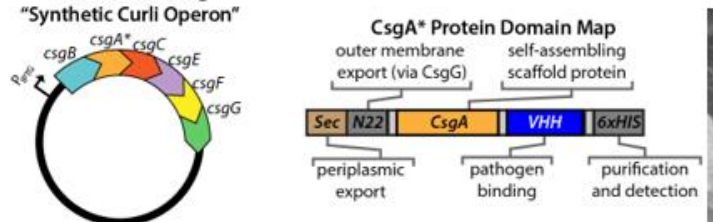

(c)
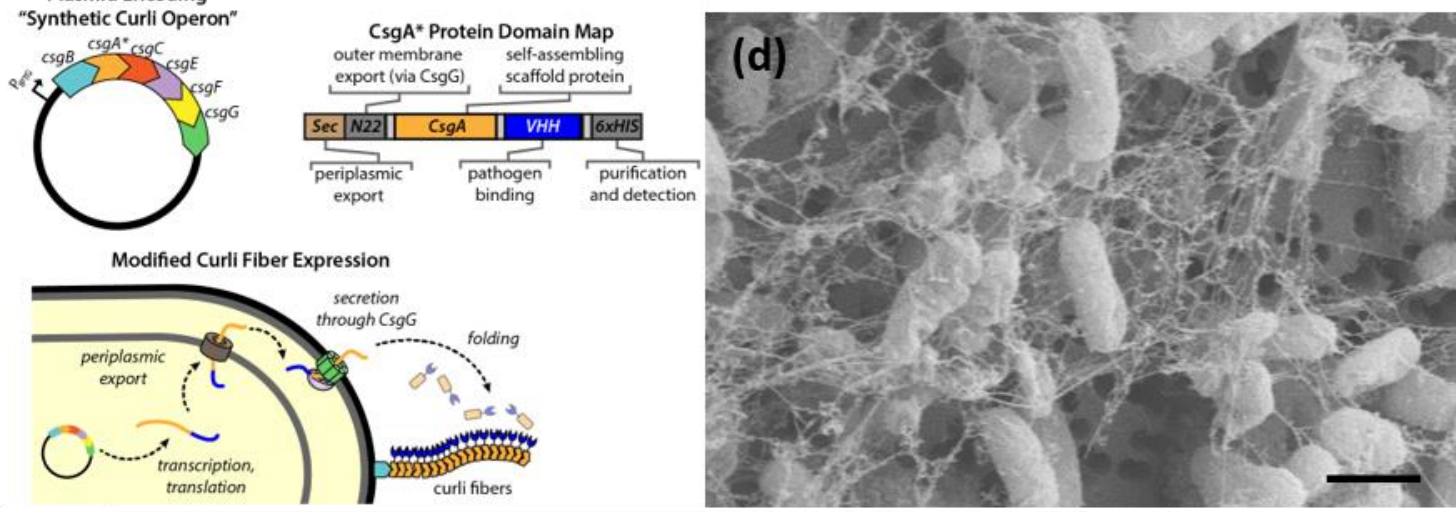

(e)

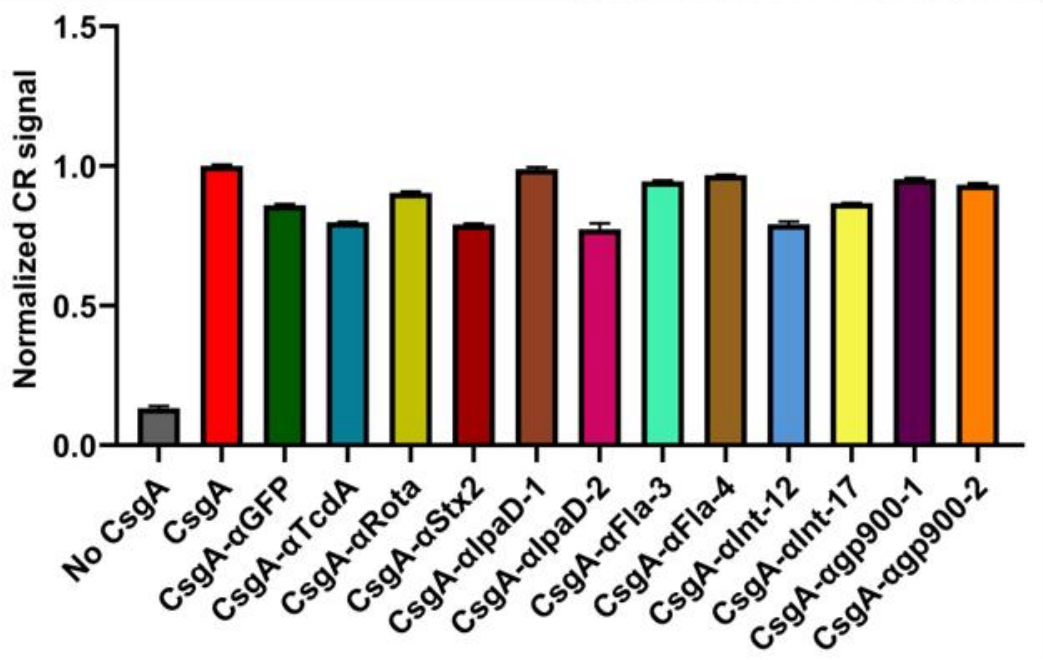

Figure 4: Formation of VHH-functionalized curli fibers by EcN. (a) Schematic overview of curli-based pathogen

sequestration approach. (b) Plasmid map of synthetic curli operon and domain map of CsgA-VHH fusion constructs. (c)

Schematic of curli fiber export and self-assembly mechanism. (d) Representative scanning electron micrograph demonstrating the formation of curli fibers by CsgA-VHH-expressing EcN (CsgA- $\alpha g p 900-2$, scale bar $=1 \mu \mathrm{m})$. (e) Congo Red (CR) binding assays 
of induced cultures of PBP8 bearing plasmids encoding various CsgA-VHH constructs. CR binding is indicative of the formation of curli amyloid fibers. Data corresponds to A490 measurements normalized to the CsgA positive control, and is presented as mean \pm SEM. Two-way ANOVA ( $\mathrm{P}<0.0001)$ was performed to test presence of difference between conditions. All CsgA constructs exhibited P-values $<0.0001$ compared to the "No CsgA" control, as calculated by Welch's t-test.

Table 2: CsgA-VHH constructs

\begin{tabular}{|c|c|c|c|}
\hline Construct Name & VHH Name & Target & VHH Source \\
\hline CsgA & N/A & N/A & N/A \\
\hline CsgA- $\alpha$ GFP & NbGFP & GFP & Rothbauer et al., 2006 [54] \\
\hline CsgA- $\alpha$ Stx 2 & JGH-G1 & Shiga toxin 2 & Tremblay et al., 2013 [25] \\
\hline CsgA- $\alpha \operatorname{Tcd} \mathrm{A}$ & NbTcdA & C. difficile toxin TcdA & Hussack et al., 2011 [55] \\
\hline CsgA- $\alpha$ Rota & $3 \mathrm{~B} 2$ & Rotavirus inner capsid protein VP6 & Vega et al., 2013 [26] \\
\hline CsgA- $\alpha$ IpaD-1 & 20ipaD & S. flexneri $\mathrm{T} 3 \mathrm{SS}$ & Barta et al., 2017 [20] \\
\hline CsgA- $\alpha$ IpaD-2 & JPS-G3 & S. flexneri T3SS & Barta et al., 2017 [20] \\
\hline CsgA- $\alpha$ Fla-3 & JUV-E8 ( $\alpha$ Fla-3) & REPEC flagellin & This study \\
\hline CsgA- $\alpha$ Fla-4 & JUV-G8 $(\alpha$ Fla-4) & REPEC flagellin & This study \\
\hline CsgA- $\alpha$ Int-12 & JWS-H4 ( $\alpha$ Int-12) & EPEC intimin & This study \\
\hline CsgA- $\alpha$ Int-17 & JWU-G8 ( $\alpha$ Int-14) & EPEC intimin & This study \\
\hline CsgA-agp900-1 & JJ-D1 & C. parvum antigen gp900 & Jaskiewicz et al., 2021 [56] \\
\hline CsgA- $\alpha g p 900-2$ & JMP-F7 & C. parvum antigen gp900 & Jaskiewicz et al., 2021 [56] \\
\hline
\end{tabular}

\section{CsgA-VHH-producing EcN binds soluble protein targets and neutralizes a bacterial toxin}

Having demonstrated the formation of curli fibers on $\mathrm{EcN}$ from engineered CsgA-VHH monomers, we next tested the functionality of the fused VHH domains. To assess the ability of curli-displayed CsgA$\alpha$ GFP to target GFP, the EcN were cultured and incubated with GFP suspended in simulated colonic fluid. After 15 minutes of incubation at $37^{\circ} \mathrm{C}$, the suspensions were pelleted, and the fluorescence of the supernatant was measured to quantify the remaining unbound GFP by comparing the signal to a calibration curve of known GFP concentrations. The unbound GFP concentration was then subtracted from the initial solution concentration to estimate bound GFP, as shown in Figure 5a. No significant binding was observed in the EcN pellet when the unfused CsgA control or an off-target (CsgA- $\alpha$ Rota) VHH was used. In contrast, upon pelleting EcN expressing CsgA- $\alpha \mathrm{GFP}$, the signal localized to the pellet was at least 56-fold higher than the negative controls, with the GFP concentration in the supernatant decreased significantly (Figure 5a). 
Shiga toxins are potent bacterial toxins comprising several variants produced by the AE pathogen EHEC, as well as by Shigella dysenteriae, and are responsible for the life-threatening manifestations of infections by these pathogens [57]. To determine if curli-VHH fibers can sequester a potent bacterial toxin from solution, we tested EcN producing a previously characterized VHH directed against Shiga toxin 2 (Stx2) [25]. EcN with curli fiber-displayed VHHs were suspended in $10 \mathrm{ng} / \mathrm{mL}$ purified Stx2 and incubated for 1 hour at $37^{\circ} \mathrm{C}$. After pelleting the EcN, monolayers of Vero cells were treated with the supernatant for 48 hours and their viability measured by a PrestoBlue cell viability assay. Supernatants derived from control EcN producing no CsgA, CsgA alone, or CsgA fused to either of two VHHs directed against irrelevant proteins (GFP or TcdA, an unrelated toxin) were toxic, yielding 20\% Vero cell viability. In contrast, incubation of Stx2 with CsgA- $\alpha$ Stx2-producing EcN significantly reduced Stx2-induced toxicity, as $\sim 75 \%$ of Vero cells survived treatment with supernatant $(\mathrm{P}<0.0001$; Figure $5 \mathrm{~b})$.

(a)

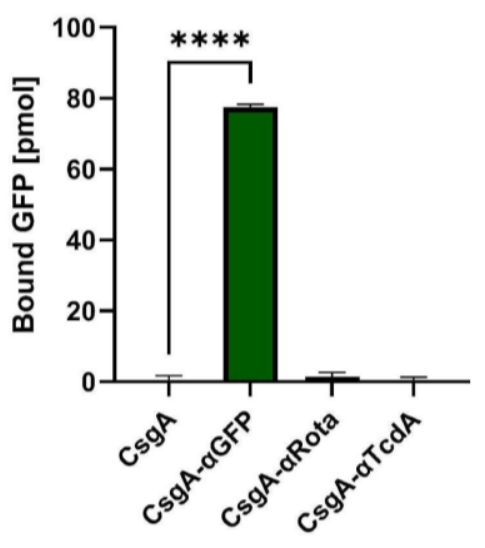

(b)

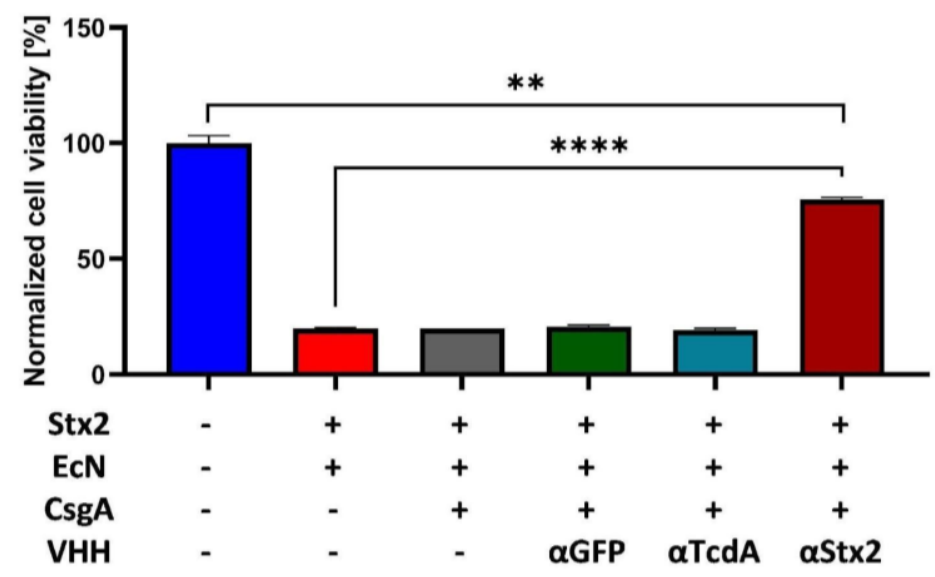

Figure 5: CsgA-VHHs can bind soluble proteins. (a) GFP pull-down assay. After incubation with $150 \mathrm{nM}$ GFP, EcN CsgA$\alpha$ GFP bound specifically to its target, as demonstrated by the depletion GFP in the cell supernatant. (b) Stx2 pull-down assay. EcN CsgA- $\alpha$ Stx 2 was used to selectively remove Stx2 upon incubation in a $10 \mathrm{ng} / \mathrm{mL} \mathrm{Stx2} \mathrm{solution.} \mathrm{Supernatants} \mathrm{were} \mathrm{added} \mathrm{to}$ Vero cell monolayers and cell viability was measured. Data presented as mean \pm SEM. Two-way ANOVA $(\mathrm{P}<0.0001)$ was performed to test presence of difference between conditions, $\mathrm{P}$-values calculated by Welch's t-test. $* * \mathrm{P}<0.01 ; * * * \mathrm{P}<0.0001$. 


\section{CsgA-VHH-producing EcN binds to targets on the cell surface of bacterial enteric pathogens}

To determine if EcN curli fiber displayed VHHs can neutralize virulence factors physically associated with pathogens, we used VHH sequences against several cell-anchored targets from multiple microorganisms and tested the ability of the VHHs to exhibit binding and/or mitigate virulence. We first generated CsgA-VHH constructs targeting the flagellar proteins of REPEC employing VHHs $\alpha$ Fla-3 and 4 which had been shown to inhibit REPEC motility (Figure 2). To test the ability of these engineered EcN strains to bind REPEC, an aggregation assay was used. When planktonic bacterial cells are added to a conical-well plate, they gradually settle to the central point at the bottom of the conical well and can be visualized as a focused pellet. In contrast, in the presence of an aggregant, cells instead form a lattice that blankets the bottom of the well uniformly, observed as diffusely distributed cells indicating microbial aggregation. Because the efficiency of aggregation is subject to the ratio of aggregant to cells, we mixed suspensions of REPEC and EcN transformants at different concentrations, then photographed the plates after allowing them to settle for a day (Figure S4). Whereas no aggregation occurred with EcN expressing three different control VHHs, VHHs $\alpha$ Fla-3 and 4 caused aggregation in a concentration and VHHdependent manner, thus demonstrating specific binding of the anti-Fla curli-VHHs to their targets. Specifically, EcN expressing CsgA- $\alpha$ Fla-3 or -4 triggered more aggregation as their concentrations increased from $0.1 \mathrm{x}$ their overnight culture density to $0.3 \mathrm{x}, 1 \mathrm{x}$, and $3 \mathrm{x}$. These same EcN suspensions did not cause aggregation when incubated with rabbit enterohemorrhagic E. coli (REHEC), a strain related to REPEC but with an antigenically distinct Fla (Figure S4), demonstrating VHH target specificity.

Flagella, which are flexible and extend 5-20 $\mu \mathrm{m}$ from the surface of E. coli, should be more easily bound by curli-displayed VHHs than structures closely associated with the microbial surface, where binding may be sterically constrained [58]. We next tested EcN expressing VHHs targeting Type III secretion systems (T3SSs), which extend less than $50 \mathrm{~nm}$ from the outer membrane of Gram-negative bacteria [59], for binding and pathogen neutralization. 
Shigella flexneri, a significant contributor to the worldwide diarrheal disease burden [2], encodes a T3SS that is essential for virulence. IpaD, which assembles at the distal end of the T3SS apparatus, prevents premature exposure of the effectors to the extracellular environment $[60,61]$. IpaD has been shown to be involved in pore formation in the host membrane by regulating IpaB and IpaC, and inhibiting IpaD function has been shown to reduce $S$. flexneri's ability to disrupt host cells [62]. Pore formation is typically evaluated using a contact-mediated hemolysis assay that measures red blood cell lysis following exposure to S. flexneri [63]. Two anti-IpaD VHHs ( $\alpha$ IpaD-1 and $\alpha$ IpaD-2, Table 2), previously shown to inhibit red blood cell lysis by S. flexneri when applied as soluble proteins [20], were expressed on EcN curli. Both curli-VHH constructs bound to soluble IpaD, although CsgA- $\alpha$ IpaD-2 exhibited a much stronger signal than CsgA- $\alpha$ IpaD-1 as measured by ELISA (Figure S5).

The ability of these curli-VHHs to neutralize S. flexneri was next tested in a hemolysis assay. Suspensions of S. flexneri were incubated with EcN expressing CsgA- $\alpha \mathrm{IpaD}-1, \mathrm{Csg} \mathrm{A}-\alpha \mathrm{IpaD}-2$, or CsgA- $\alpha \mathrm{GFP}$ (negative control). As a positive control, we prepared a soluble trimer of $\alpha \mathrm{IpaD}$ VHHs (Figure 6). Following incubation of EcN with Shigella, bacterial suspensions were exposed to sheep blood, and hemolysis was measured colorimetrically. EcN producing CsgA- $\mathrm{IpaD}-2$ abolished much of the observed hemolysis, as did the positive control. Surprisingly, we did not obtain similar results with CsgA- $\alpha$ IpaD-1, despite its ability to bind soluble IpaD (Figure 6), suggesting this VHH may be sterically inhibited from binding Shigella TS33 when expressed on curli fibers.

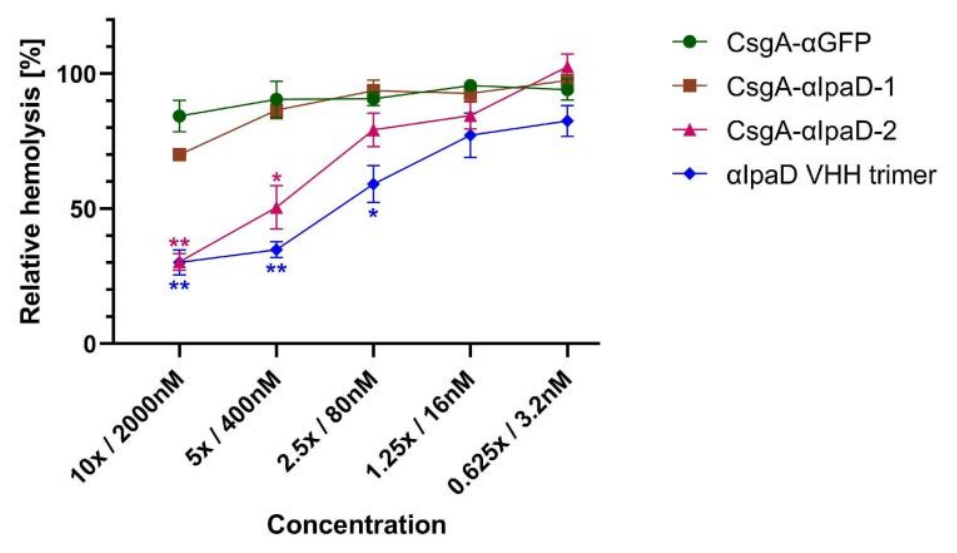


Figure 6: CsgA-VHHs can neutralize S. flexneri contact-mediated hemolysis. EcN expressing CsgA- $\alpha$ IpaD-2, but not CsgA$\alpha \mathrm{IpaD}-1$, inhibited hemolysis of sheep red blood cells, significantly outperforming the off-target negative control (CsgA- $\alpha \mathrm{GFP})$. Data presented as mean \pm SEM. Two-way ANOVA $(\mathrm{P}<0.0001)$ was performed to test the presence of difference between conditions, $\mathrm{P}$-values calculated by Welch's tclam-test. * $\mathrm{P}<0.05 ; * * \mathrm{P}<0.01$.

\section{CsgA-VHH-producing EcN can bind to the eukaryotic pathogen Cryptosporidium parvum}

To determine if EcN curli fiber displayed VHHs can bind to a protein target on the surface of a eukaryotic pathogen, we utilized the parasite Cryptosporidium parvum, which, along with $C$. hominis, is the major cause of cryptosporidiosis. Cryptosporidiosis is an enteric diarrheal disease, a major cause of morbidity in children in low-income countries [1,2], and is the leading cause of waterborne disease in the United States with the number of infections continuing to rise [64]. Cryptosporidiosis can also be severe in immunocompromised individuals such as those living with AIDS/HIV, where the prevalence of enteric protozoan infection was reported to be $30.6 \%$ [65]. Novel treatments for cryptosporidiosis are urgently needed, as nitazoxanide, the only available treatment, has limited efficacy and is effective in only a subset of patients [66].

Because of the difficulty of studying and propagating human pathogenic Cryptosporidium spp., relatively few documented virulence factors or well-characterized surface-exposed antigens are known compared to many other enteric pathogens. One such antigen, glycoprotein gp900, is expressed on the surface of $C$. parvum sporozoites and has been reported to be a virulence factor due to its roles in motility and host cell invasion [67]. Importantly, gp900 is also shed in trails by sporozoites as they move about.

Previous studies identified VHHs that recognize the carboxyl-terminal domain of gp900 (agp900-1 and agp900-2, Table 2) [56]. We used both VHH sequences to generate CsgA fusions, produced these in EcN, and tested their ability to bind their target antigen. We first tested gp900 binding using an ELISA, where CsgA-VHH-expressing EcN were adsorbed onto plastic and incubated with C. parvum lysate. EcN that expressed CsgA-agp900-2, though not CsgA-agp900-1, produced a weak binding signal indicating 
binding at high concentrations, significantly different from the CsgA- $\alpha$ GFP negative control (Figure 7a).

Similarly, in a pull-down assay, EcN expressing CsgA-agp900-2, but not agp900-1, depleted gp900 from C. parvum lysate (Figure 7b).

Binding to the parasites was then assayed by fixing C. parvum sporozoites onto slides, exposing them to $\mathrm{EcN}$, and quantifying the parasite-bound EcN. Interestingly, while CsgA- $\alpha g p 900-1$ did not appear to bind the antigen in its soluble form, it significantly outperformed CsgA- $\alpha g p 900-2$ in pathogen binding, although CsgA- $\alpha$ gp900-2 also bound the parasites significantly better than the CsgA- $\alpha$ GFP negative control (Figure 7c). Qualitatively, colocalization of EcN CsgA- $\alpha g p 900$ with the fixed sporozoites was also observed (Figure S6).

(a)

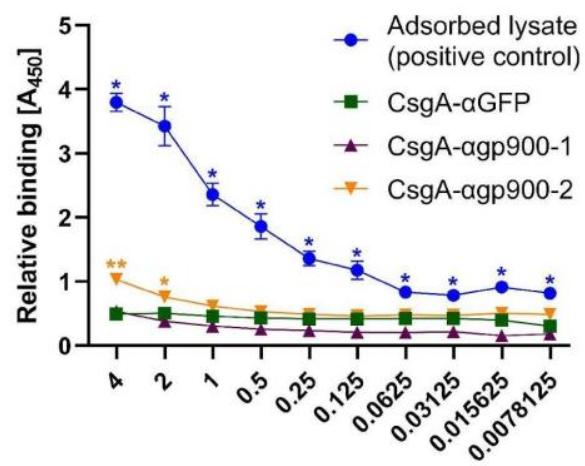

Lysate concentration $[\mu \mathrm{g} / \mathrm{mL}]$ (b)

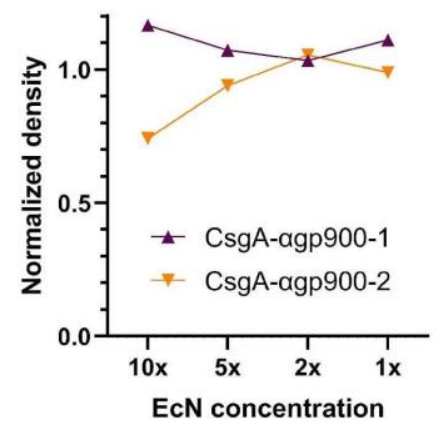

(c)

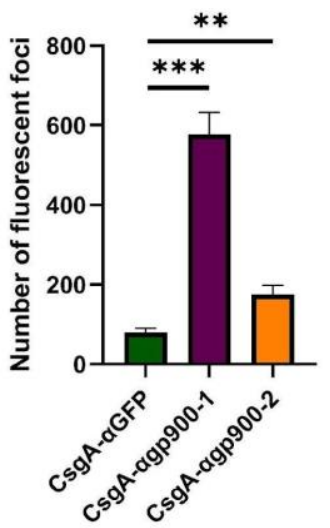

Figure 7: CsgA-VHHs can bind to the eukaryotic pathogen Cryptosporidium parvum. (a) ELISA demonstrating the ability of CsgA-agp900-2 to bind gp900. EcN was adsorbed onto a well plate, followed by incubation with gp900-containing C. parvum lysate. In the positive control, no $\mathrm{EcN}$ was used, and the C. parvum lysate was allowed to directly adsorb onto the surface of the wells. Gp900, either bound to EcN or adsorbed to the surface, was detected using a non-competing anti-gp900 VHH, followed by an anti-Etag IgG-HRP conjugate. (b) Western blot analysis of gp900 binding to CsgA- $\alpha$ gp900-2. C. parvum lysate was incubated with $\mathrm{EcN}$ at different concentrations. After pelleting the $\mathrm{EcN}$, supernatant form was run on gel and subjected to Western blot to assess gp900 depletion. The gp900 band was detected by a specific non-competing VHH, followed by an anti-Etag IgG-HRP conjugate. Band intensity was normalized to a CsgA- $\alpha$ GFP negative control. (c) CsgA- $\alpha$ gp900-1 and -2 bind to C. parvum sporozoites. EcN was applied to immobilized and fixed sporozoites, followed by staining with anti-LPS Mab and anti-mouse IgG 
Alexa Fluor 568. Slides were inspected under TRITC filter and 5 images were taken under 200x magnification for each condition. Foci of EcN accumulation were quantified using ImageJ particle analyzer. Data presented as mean \pm SEM. Two-way ANOVA ( $\mathrm{P}<0.0001)$ was performed to test presence of difference between conditions, P-values calculated by Welch's t-test. * $\mathrm{P}<0.05 ; * * \mathrm{P}<0.01 ; * * * \mathrm{P}<0.001$.

\section{Discussion}

In this report we propose a novel approach, which we term 'curli-based pathogen sequestration', to treat or prevent enteric infectious disease. By appending VHH domains to curli fibers and displaying these modified fibers on the probiotic strain EcN, we demonstrated binding, and in some cases, neutralization, of virulence factors produced by several different pathogens. These factors include the potent enteric bacterial toxin Stx2, the flagella of REPEC, the T3SS of S. flexneri, and the surface antigen gp900 of the eukaryotic parasite C. parvum. In addition, we described the identification and characterization of VHHs that bind to various surface-exposed EPEC or EHEC virulence factors. These VHHs include those that inhibited flagella-driven motility or interfered with Tir-intimin binding and exhibited neutralizing activity against their target pathogen. Adding to the growing body of validated VHH sequences, these antibodies may find use in myriad therapeutic, diagnostic, and research applications, and contribute to the study and treatment of pathogenic E. coli.

We propose here the further exploration of $\mathrm{EcN}$ curli fiber-displayed VHHs as a potential strategy for the prevention of enteric pathogen establishment. We suggest that by maintaining a level of EcN-displayed anti-pathogen VHHs on curli fibers, the probiotic bacteria may sequester incoming pathogens in the GI tract before they reach their target sites of infection, allowing their elimination from the body by natural processes without causing pathology. The use of EcN-displayed VHHs that bind essential virulence factors, and thus neutralize the ability of the pathogen to infect the host, could add additional protection.

The efficacy of curli-based sequestration has not yet been tested in vivo, and requires further validation. Specifically, such validation will necessitate the development of animal infection models that support 
coadministration and maintenance of pathogens and $\mathrm{EcN}$ at stable levels, allowing for testing of the efficacy of the curli-based sequestration matrix. Nevertheless, our approach has several features that make it particularly well-suited for binding enteric pathogens in situ. First, the curli matrix can provide multivalent display of pathogen binding domains, as each of the stacked CsgA monomers is linked to a VHH domain. Multivalency has been shown to be an important factor for enhancing the performance of several pathogen binding systems [25, 68-71]. Secondly, curli-based materials have been demonstrated to work in the gastrointestinal tract, both in the form of anti-inflammatory peptides displayed on curli fibers produced by EcN [43], as well as similarly functionalized curli hydrogels [72].

Additionally, because $\mathrm{EcN}$ can replicate in the host and continuously produce new curli fibers, we anticipate that steady-state levels of the displayed VHH multimers can be maintained for significant periods of time despite the harsh proteolytic environment and constant flow in the gut. Notably, the ability of EcN to maintain a steady-state density in the mammalian GI tract with regular dosing is supported by data in mice and humans [35, 40]. Progress has also been made using EcN in clinical trials as an engineerable chassis organism for therapeutic applications in the gut [73-76].

Lastly, the use of engineered microbes to deliver and produce the sequestrant in situ may offer additional benefits. Unlike inert biomaterials, bacteria can sense their environment and respond to changes within it. As such, engineered living therapeutics can exert additional therapeutic or diagnostic functions in tandem with the production of pathogen-binding molecules - either in the form of genetic circuits or through their inherent native properties. In particular, the use of $\mathrm{EcN}$ as a chassis organism may prove advantageous in targeting EPEC and EHEC variants, as it has been shown to outcompete these strains in biofilm formation [38], prevent EHEC colonization in mice by occupying a similar nutritional niche [77], as well as promote intestinal health through several other mechanisms [78]. Therefore, while further studies are needed, we hypothesize that the pathogen sequestration strategy may work synergistically with EcN's probiotic functions, potentially resulting in a more effective treatment than either wild-type $\mathrm{EcN}$ or a non-living curli-VHH material. 
Notably, not all CsgA-VHH constructs proved equally efficacious. For instance, while both anti-IpaD VHHs exhibited neutralizing activity in their soluble form [20], only CsgA- $\alpha$ IpaD-2 retained this ability when displayed on EcN-bound curli fibers. This difference may be due to steric effects related to the spatial arrangement of neighboring VHHs fused to CsgA domains. Alternatively, the variation may be related to CsgA-VHH secretion and curli fiber assembly as translocation of some VHH domains through the curli secretion machinery may interfere with proper protein folding. The curli secretion and assembly pathway involves multiple steps and requires translocation through the inner membrane into the periplasm via the SecYEG translocon, followed by transit through the dedicated CsgG outer membrane pore [79]. While this pathway has been shown to accommodate various CsgA fusions, the complete scope of specific limitations of this capacity are yet to be fully elucidated [80]. Nevertheless, the impressive amenability of the CsgG outer membrane pore to a wide variety of VHH fusions demonstrates the modularity and flexibility of functionalized curli in general, and VHH-based applications specifically.

In recent years, other pathogen sequestration approaches have been explored for the binding and removal of viruses from patients or the environment. Dey and coworkers developed synthetic polymer nanogels that were able to bind herpes simplex virus 1 and block its ability to infect mammalian cells in vitro [71]. More recently, $\mathrm{Pu}$ and coworkers fused an influenza-binding peptide to curli fibers and demonstrated their ability to remove virus particles from contaminated water [81]. Strategies based on feeding VHHs or VHH multimers have also been reported and have shown promise for treating the pathology of enteric pathogen infections $[18,19,22]$.

Successful deployment of VHH-based therapeutics against enteric pathogens to locations where they are most needed will require cheap manufacturing and the need for only a limited medical infrastructure to support their effective use. Our engineered probiotic approach has the potential to satisfy these requirements. Though the bacteria may need proper formulation, they should not require substantial purification steps or an onerous cold chain for distribution. Furthermore, recent animal and human trial results suggest that daily oral administration can maintain a steady-state concentration of EcN in the GI 
tract $[35,40]$, and that bacterial counts drop rapidly after ceasing administration - a useful safety feature of this approach. The prospect of local delivery inside the gut would also minimize off-target effects and side effects that result from systemic delivery while offering the additional health benefits of conventional probiotics. Since our approach is not bactericidal, it also has interesting implications for circumventing the development of antibiotic resistance that will warrant further investigation.

\section{Materials and Methods}

\section{Cell strains and plasmids}

All strains and plasmids used in this study are summarized in Supplementary Tables S\#\#\# and S\#\#\#.

\section{Bacterial culture}

All E. coli and C. rodentium strains were cultured in LB broth at $37^{\circ} \mathrm{C}$ at $225 \mathrm{RPM}$, unless otherwise specified. EcN (PBP8) strains were streaked from frozen stock onto selective lysogeny broth (LB) agar plates and grown overnight at $37^{\circ} \mathrm{C}$. Cultures were subsequently started from single colonies into $5 \mathrm{~mL}$ LB supplemented with $50 \mu \mathrm{g} / \mathrm{mL}$ kanamycin and grown overnight at $37^{\circ} \mathrm{C}$ with shaking at $225 \mathrm{RPM}$. The following day, overnight cultures were diluted 1:100 into $10 \mathrm{~mL}$ fresh media and grown at $37^{\circ} \mathrm{C}$ and 225 RPM, and protein expression was induced by adding $100 \mu \mathrm{M}$ isopropyl $\beta$-D-1-thiogalactopyranoside (IPTG). Induced cultures were grown overnight.

Shigella flexneri was streaked from frozen stock onto tryptic soy agar (TSA) plates supplemented with $0.02 \%$ Congo Red (CR) and grown overnight at $37^{\circ} \mathrm{C}$. The following day, 3 colonies were used to inoculate $50 \mathrm{~mL}$ of tryptic soy broth (TSB) in a baffled flask. Only colonies stained red by CR were used. The culture was grown at $37^{\circ} \mathrm{C}$ and $225 \mathrm{RPM}$ to OD at $600 \mathrm{~nm}$ of $0.8-1.0$, placed on ice upon reaching the desired OD, pelleted at $3500 \mathrm{RPM}$ for 10 minutes at $4^{\circ} \mathrm{C}$, and resuspended in $5 \mathrm{~mL}$ to obtain a $10 \mathrm{x}$ suspension. 


\section{Mammalian cell culture}

HeLa cells (ATCC CCL-2) were maintained in Dulbecco's modified Eagle's medium (DMEM) with 10\% fetal bovine serum (FBS) and $1 \%$ Penicillin-Streptomycin antibiotics in a 5\% $\mathrm{CO} 2$ incubator at $37^{\circ} \mathrm{C}$. For infection, 30,000 cells were seeded on 24 -well plates in a volume of $0.5 \mathrm{~mL} /$ well. The next day, cells were gently washed with PBS before inoculating with bacteria. Vero cells (ATCC CCL-81) were grown in Eagle's Minimum Essential Medium (EMEM) supplemented with 10\% FBS in a 5\% CO2 incubator at $37^{\circ} \mathrm{C}$. For Stx 2 toxicity assays, Vero cells were seeded on 96 -well plates one day prior to incubation with toxin.

\section{Parasite propagation}

C. parvum oocysts, MD isolate originating from deer and passaged repeatedly in sheep and mice [82], were generated at Tufts University by propagation in CD-1 mice as described elsewhere [83], in compliance with study protocol No. G2017-107 approved by the Tufts University Institutional Animal Care Use Committee. Prior to excystation, oocysts were bleached on ice for 7 minutes using 5\% dilution of commercial bleach (Clorox Original, The Clorox Company, CA). To remove bleach, oocysts were washed three times by suspension in PBS and centrifugation $(18,000 \times \mathrm{g}, 2 \mathrm{~min})$.

\section{Purification of flagella}

Flagella from REPEC (E22), EPEC (E2348/69), and E10 (O119:H6) were isolated as described previously [84], with slight modification. Briefly, a single colony was transferred into $5 \mathrm{~mL}$ LB broth and incubated overnight at $37^{\circ} \mathrm{C}$ with continuous shaking. The next day, the culture was diluted 1:100 into LB broth and grown at $37^{\circ} \mathrm{C}$ to $\mathrm{OD}_{600}$ of $0.5 .100 \mu \mathrm{L}$ of the culture was plated onto the surface of eighty $100 \mathrm{~mm}$ diameter LB agar plates and incubated for $24 \mathrm{~h}$ at $37^{\circ} \mathrm{C} .500 \mu \mathrm{L}$ of PBS was then added to each plate and a glass slide was used to gently scrape bacteria from the agar plate. Bacteria were collected in a centrifuge bottle. To shear flagella from the bacteria, the centrifuge bottle was manually shaken for 2 min and then shaken for 5 mins at $4^{\circ} \mathrm{C}$ at $220 \mathrm{RPM}$. The bottle was then centrifuged at $7025 \times \mathrm{g}$ for $20 \mathrm{~min}$ at 
$4^{\circ} \mathrm{C}$ to remove cell debris. Bacteria-free supernatant was transferred to a new centrifuge bottle, which was further centrifuged at $25,402 \times \mathrm{g}$ for 1 hour at $4^{\circ} \mathrm{C}$ to precipitate flagella. To recover flagella, the supernatant was removed, and the pellet was resuspended in $500 \mu \mathrm{L}$ of ice-cold PBS. To confirm that the purified flagella encompassed flagellin monomers of $60 \mathrm{kDa}$, flagella were visualized by sodium dodecyl sulphate polyacrylamide gel electrophoresis (SDS-PAGE) and by Western blotting using Rabbit anti-H6 flagella antibody. Note: EPEC E2348/69 produces fewer flagella filaments when grown in LB media [51]. Therefore, to maximize shearing of flagella from E2348/69, bacteria were either passed through a syringe and a 22-gauge needle or heat treated at $65^{\circ} \mathrm{C}$ for 30 mins.

\section{Alpaca immunizations}

Immunizations were performed essentially as described by Vrentas et al. [85]. Two different pairs of alpacas were each immunized in two separate rounds of immunization with various combinations of purified REPEC or EPEC flagella, and/or recombinant proteins MBP/EHEC intimin, or 6xHis/EHEC Tir. For each round of immunization, five successive multi-site subcutaneous injections were employed at about 3-week intervals. Blood was obtained for lymphocyte preparation 3-5 days after the fifth immunization and RNA was prepared from lymphocytes using the RNeasy kit (Qiagen, Valencia, CA). A VHH-display phage library was prepared essentially as described previously [70] following each of the rounds of alpaca immunization, yielding libraries with complexities of about 1-2 x $10^{7}$ independent clones, and $>95 \%$ containing VHH inserts.

\section{Identification and purification of VHHs}

Phage library panning methods have been previously described [86]. Typically, the virulence factor proteins were coated onto plastic at $10 \mu \mathrm{g} / \mathrm{mL}$ of target in the first panning round, followed by a second round of panning at high stringency, with virulence factor proteins coated at $1 \mu \mathrm{g} / \mathrm{mL}$, and using a 10 -fold lower titer of input phage, shorter binding times, and longer washes. In some cases, the virulence factor targets were captured onto plastic by previously coated VHHs which bind the target or its fusion partner. 
VHH capture panning was also used in some cases to block isolation of VHHs to immunodominant epitopes on monomeric targets. Random clones from the selected populations were then screened by ELISA for expression of VHHs that bound to the virulence factor targets. Clones producing the strongest signals or showing broader target specificity were characterized by DNA fingerprinting. The coding sequences of VHHs selected as having unique fingerprints and the strongest ELISA signals were obtained. Based on sequence homology, one VHH representing each homology group (having no evidence of a common B cell clonal origin) was selected for expression and characterization. These VHHs were expressed individually in pET32 vectors and purified as recombinant $E$. coli thioredoxin fusions with a carboxy-terminal E-tag, as previously described [86].

\section{Dilution ELISA}

ELISAs were performed using Nunc Maxisorp 96 well plates (Thermo Fisher Scientific). Virulence factor targets were typically coated overnight at $4^{\circ} \mathrm{C}, 1 \mu \mathrm{g} / \mathrm{mL}$ in PBS, then blocked for at least an hour at $37^{\circ} \mathrm{C}$ with $4 \%$ milk in PBS, $0.1 \%$ Tween. For capture ELISAs, plates were first coated with $5 \mu \mathrm{g} / \mathrm{mL}$ of VHHs that recognized the virulence factor or its fusion partner. The captured VHHs lacked both the thioredoxin partner and E-tag. After blocking, the virulence factor was then incubated at $1 \mu \mathrm{g} / \mathrm{mL}$ for one hour at $37^{\circ} \mathrm{C}$ with $4 \%$ milk in PBS, $0.1 \%$ Tween and washed. Dilution ELISAs were then initiated by diluting the VHH (expressed in a pET-32 vector with an amino terminal thioredoxin and a carboxyl terminal E-tag) to $125 \mathrm{nM}$ and performing serial dilutions of $1: 5$. After incubation for one hour at $37^{\circ} \mathrm{C}$, plates were washed and then incubated with 1:10,000 rabbit HRP/anti-E-tag (Bethyl Laboratories) for one hour, washed, developed with TMB (Sigma Aldrich) as recommended by the manufacturer and measured for absorbance at $450 \mathrm{~nm}$.

\section{ELISA measuring the effect of anti-Tir VHHs on the intimin-Tir interaction}

The ability of anti-Tir VHHs derived from EHEC to interfere with intimin-Tir binding was measured by ELISA. High-binding assay plates (Corning) were coated with $5 \mu \mathrm{g} / \mathrm{mL}$ of recombinant his-tagged Tir 
diluted in $1 \mathrm{x}$ coating buffer $(50 \mathrm{mM} \mathrm{Na} 2 \mathrm{CO} 3,50 \mathrm{mM} \mathrm{NaHCO}$, pH 9.6) in a volume of $100 \mu \mathrm{L}$ per well and incubated overnight at $4{ }^{\circ} \mathrm{C}$. Plates were washed three times with $300 \mu \mathrm{L}$ of wash buffer $(0.05 \%$ Tween in PBS) and then blocked with BSA (3\% in PBS) for 2 hours at room temperature (RT). Plates were washed and $100 \mu \mathrm{L}$ of $500 \mathrm{nM}$ anti-Tir VHH were added to each well. $0.1 \%$ BSA was used as a negative control. Plates were incubated at RT for 2 hours or at $4^{\circ} \mathrm{C}$ overnight. Wells were then probed with $150 \mathrm{nM}$ GST-tagged intimin or with GST alone, and incubated at RT for 2 hours or at $4^{\circ} \mathrm{C}$ overnight. Plates were washed again and then fixed with $3.7 \%$ paraformaldehyde at RT for 20 mins at $4{ }^{\circ} \mathrm{C}$. Following another wash, plates were blocked with 5\% milk in PBS for $30 \mathrm{~min}$ at RT. After washing, plates were incubated with goat anti-GST (GE Healthcare) for an hour and GST binding was detected kinetically using an alkaline-phosphatase-linked rabbit anti-goat IgG secondary antibody (diluted 1:2000 in $0.1 \% \mathrm{BSA} / \mathrm{PBS}$ ). Binding of the secondary antibody was detected colorimetrically (AP substrate N1891, Sigma Aldrich) at $405 \mathrm{~nm}$, and the average reaction rate $\left(\mathrm{V}_{\text {mean }}\right)$ was calculated.

\section{REPEC motility assay}

Motility assays were performed as described previously [70], with slight modification, to measure the ability of anti-Fla VHHs to inhibit Rabbit Enteropathogenic Escherichia coli (REPEC) motility. Briefly, REPEC cultures were streaked on LB agar plates and incubated for 16 hours at $37^{\circ} \mathrm{C}$. The next day, a single colony was transferred into $5 \mathrm{~mL}$ LB broth and incubated overnight at $37^{\circ} \mathrm{C}$ with continuous shaking. On the following day, the culture was diluted 1:50 into LB broth and grown at $37^{\circ} \mathrm{C}$ with continuous shaking to an $\mathrm{OD}_{600}$ of 0.5 . A 1:1 dilution of bacteria and VHHs was then prepared $(6 \mu \mathrm{L}$ of bacterial culture was mixed with $6 \mu \mathrm{L}$ of $\mathrm{VHH}$ concentrations ranging from 0 to $6.4 \mu \mathrm{M}$ ), mixed gently with a pipette, and incubated at $4^{\circ} \mathrm{C}$ for $2 \mathrm{~h}$. The $12 \mu \mathrm{L}$ mixture was then transferred to the center surface of a $0.3 \%$ semi solid agar plate and incubated for $24 \mathrm{~h}$ at room temperature. The diameter of bacterial growth was measured by first placing the plate on a dark background to enhance the contrast between bacterial growth and the agar medium. A metric scale ruler was then used to measure the growth diameter. Images were captured using a Syngene imager. 
To test the ability of EcN-produced CsgA-VHH to inhibit REPEC motility, the above procedure was modified to embed induced $\mathrm{EcN}$ suspensions in the semi-solid agar medium. For each EcN variant, 50 $\mathrm{mL}$ of culture were grown and induced as previously described. Each culture was pelleted and resuspended in $1 \%$ tryptone $0.5 \% \mathrm{NaCl}$ media supplemented with $200 \mu \mathrm{g} / \mathrm{mL}$ carbenicillin to prevent EcN growth. Each plate was filled with $12.5 \mathrm{~mL}$ EcN suspension followed by $12.5 \mathrm{~mL} 0.6 \%$ agar media, for a final plate composition of $1 \%$ tryptone, $0.5 \% \mathrm{NaCl}, 0.3 \%$ agar, $100 \mu \mathrm{g} / \mathrm{mL}$ carbenicillin and CgsAVHH dispersed throughout the volume of the plate. For this assay, REPEC was transformed with the KAG plasmid to confer carbenicillin resistance as well as constitutive GFP expression to better distinguish it from EcN biomass. Images were acquired at several time points over a 48-hour period using a GelDoc imaging system (Bio-Rad).

\section{EPEC pedestal assay}

The ability of anti-intimin and anti-Tir VHHs to inhibit EPEC pedestal formation was assessed after infection of HeLa cells, as described previously [87], with slight modification. Briefly, 30,000 HeLa cells were inoculated into the wells of 24-well plates (Invitro Scientific,) and incubated overnight at $37^{\circ} \mathrm{C}$ in an incubator with 5\% $\mathrm{CO} 2$. On the same day, a single EPEC colony was inoculated into $5 \mathrm{~mL}$ DMEM in 100mM HEPES medium (pH 7.4) and incubated overnight in $5 \% \mathrm{CO} 2$ at $37^{\circ} \mathrm{C}$ without shaking. The next day, the EPEC culture was diluted 1:16 into new infection medium $(0.6 \mu \mathrm{L}$ EPEC added to $9.4 \mu \mathrm{L}$ media containing DMEM, $20 \mathrm{mM}$ HEPES, and 3.5\% FBS; pH 7.4), and $3.33 \mu \mathrm{L}$ of the EPEC suspension were incubated either alone or with $100 \mathrm{nM}$ anti-Tir or anti-intimin VHH in $0.5 \mathrm{~mL}$ DMEM at $4^{\circ} \mathrm{C}$ for 2 hours, in $1.5 \mathrm{~mL}$ Eppendorf tubes on a rocker. HeLa cell monolayers were then washed with $0.5 \mathrm{~mL}$ PBS, and EPEC suspensions were added to the monolayers. Plates were then centrifuged at 500 RPM for 5 min and incubated for $3 \mathrm{~h}$ at $37^{\circ} \mathrm{C}$ in a $5 \% \mathrm{CO} 2$ incubator. Next, cells were washed twice with PBS, fixed with 0.5 $\mathrm{mL} 2.5 \%$ paraformaldehyde in PBS for 10 mins at RT on a shaker, washed twice with PBS for 5 min on a shaker at RT, permeabilized with $0.5 \mathrm{~mL}$ of $0.1 \%$ TritonX-100 for $5 \mathrm{~min}$, and washed twice again before staining with DAPI (Thermo Fisher Scientific) and Alexa Fluor-488 Phalloidin (Thermo Fisher 
Scientific) at RT for 1.5 hours. Monolayers were then washed and $7 \mu \mathrm{L}$ prolong gold anti-fade reagent (Thermo Fisher Scientific) was used to mount coverslips on wells before imaging with a fluorescent microscope.

EPEC pedestal formation was blindly scored, as follows; 1: Very few pedestals are present on the edges of the wells, 2: More pedestals present, only at the edges of the well, 3: Most cells have no pedestals, but a few pedestals present in the center and edges of wells, 4: Most cells have pedestals, but a few empty cells are present, 5: The majority of the cells have pedestals. Using the above numbering criteria, pedestals were scored blindly by a second researcher.

\section{CsgA-VHH plasmid construction and cloning}

The cloning of the synthetic curli operon $\operatorname{csg} B A C E F G$ onto the pL6FO vector was described in detail elsewhere [88]. DNA sequences of desired VHHs and corresponding primers were synthesized by and purchased from Integrated DNA Technologies. Plasmid construction was carried out using Gibson Assembly [89].

\section{Quantitative Congo Red binding assay}

Curli fiber formation was quantified using a Congo Red binding assay as previously described [43].

Briefly, $1 \mathrm{~mL}$ of induced EcN CsgA-VHH culture was pelleted at $4000 \times \mathrm{g}$ for 10 minutes at room temperature and resuspended in a $25 \mu \mathrm{M}$ Congo Red PBS solution. After a 10-minute incubation, the cell suspension was pelleted again, and the unbound Congo Red dye was quantified by measuring the supernatant absorbance at $490 \mathrm{~nm}$. The signal was subtracted from a Congo Red blank, divided by the culture's $\mathrm{OD}_{600}$ measurement to reflect curli production per cell, and normalized with respect to a EcN CsgA (no VHH) positive control. 


\section{Electron microscopy}

Field emission scanning electron microscope (FESEM) samples were prepared by fixing with 2\% (w/v) glutaraldehyde and 2\% (w/v) paraformaldehyde at room temperature, overnight. The samples were gently washed with water, and the solvent was gradually exchanged with ethanol with an increasing ethanol 15minute incubation step gradient $(25,50,75$ and $100 \%(\mathrm{v} / \mathrm{v})$ ethanol). The samples were dried in a critical point dryer, placed onto SEM sample holders using silver adhesive (Electron Microscopy Sciences) and sputtered until they were coated in a 10-20 nm layer of Pt/Pd. Images were acquired using a Zeiss Ultra55 FESEM equipped with a field emission gun operating at 5-10 kV.

\section{GFP pull-down assay}

For each condition, $1 \mathrm{~mL}$ of induced overnight culture was centrifuged at $4000 \times \mathrm{g}$ for 10 minutes. The supernatant was aspirated, and the pellets were resuspended in $150 \mathrm{nM} \mathrm{GFP}$ in fasted-state simulated colonic fluid, which was prepared as described by Vertzoni et al. [90]. The cells were incubated on a shaking platform $(225 \mathrm{RPM})$ at $37^{\circ} \mathrm{C}$ for 15 minutes and pelleted again. The GFP remaining in solution was assayed by measuring the fluorescent signal $(485 \mathrm{~nm} / 528 \mathrm{~nm})$ using a plate reader (Spectramax M5, Molecular Devices). GFP concentration was estimated based on a calibration curve using known GFP concentrations.

\section{Shiga toxin pull-down assay}

Induced $\mathrm{EcN}$ cultures were pelleted at $4000 \times \mathrm{g}$ for 10 minutes and resuspended in $10 \mathrm{ng} / \mathrm{mL}$ of Stx2 in PBS. The bacterial suspensions were then serially diluted tenfold (from 1:10 to 1:10 ${ }^{4}$ in $10 \mathrm{ng} / \mathrm{mL}$ Stx2 PBS solution, maintaining a constant Stx 2 concentration. The suspensions were incubated $37^{\circ} \mathrm{C}$ on a 225 RPM rotating platform for 1 hour and pelleted again. For each condition, $10 \mu \mathrm{L}$ of supernatant were added to $90 \mu \mathrm{L}$ of Vero cell medium in its corresponding well. After a 48 -hour incubation at $37^{\circ} \mathrm{C}$ with $5 \% \mathrm{CO}_{2}, 10 \mu \mathrm{L}$ of PrestoBlue Cell Viability Reagent (Thermo Fisher Scientific) was added into each well, followed by a 10 -minute incubation and measurement of fluorescent signal at $560 \mathrm{~nm} / 590 \mathrm{~nm}$. 


\section{REPEC and REHEC aggregation assays}

REPEC, REHEC and EcN were cultured as previously described. Cultures were pelleted and resuspended in PBS to obtain $3 \mathrm{x}, 1 \mathrm{x}, 0.3 \mathrm{x}$ or $0.1 \mathrm{x}$ suspensions as compared to the original culture density. Cell suspensions were subsequently mixed and added into 96-well conical-bottom microwell plates (Thermo Fisher Scientific) and allowed to settle overnight at room temperature prior to imaging.

\section{Generation of anti-IpaD VHH trimer}

VHH heterotrimer was designed and generated as previously described [91, 92]. Briefly, DNA encoding the 20ipaD, JMJ-F5, and JPS-G3 VHHs [20] separated by 15-amino acid flexible glycine-serine linkers $\left((G G G G S)_{3}\right)$ was synthesized (GenScript Biotech, Piscataway, NJ) and ligated into pET32b(+) vector between the N-terminal thioredoxin (trx) fusion partner and a C-terminal E-tag epitope. VHH trimer was expressed in E. coli Rosetta-gami 2(DE3)pLac1 (Novagen) by overnight incubation in $1 \mathrm{mM}$ IPTG, followed by lysis and purification on nickel agarose resin (Invitrogen). Bound VHHs were eluted from resin using increasing concentrations of imidazole ranging from $10 \mathrm{mM}$ to $250 \mathrm{mM}$.

\section{Shigella contact-mediated hemolysis assay}

To determine the ability of CsgA-VHH to inhibit Shigella virulence activity, a contact-mediated hemolysis assay was carried out as previously described [62], with slight modification. Prior to exposure of $S$. flexneri to red blood cells, induced EcN cultures were pelleted and resuspended in PBS to obtain a 10x concentrated cell suspension, which was subsequently serially diluted to yield $5 \mathrm{x}, 2.5 \mathrm{x}, 1.25 \mathrm{x}$ and $0.625 \mathrm{x}$ suspensions. The pathogen was then incubated for $30 \mathrm{~min}$ at room temperature with either the EcN suspensions or the abovementioned anti-IpaD VHH heterotrimer (trx/20ipaD/JMJ-F5/JPS-G3/E) as a positive control, in concentrations between 3.2-2000 nM. 


\section{Preparation of Cryptosporidium lysate}

Pre-bleached C. parvum oocysts were excysted in $0.75 \%$ taurocholic acid suspension in PBS for $1 \mathrm{~h}$ at $37^{\circ} \mathrm{C}$. Following centrifugation $(18,000 \times \mathrm{g}, 2 \mathrm{~min})$, supernatant was collected and the pelleted sample consisting of sporozoites, unexcysted oocysts and oocyst shells was then sonicated (Qsonica CL5, Qsonica Sonicators, USA) with thirty cycles, 20 seconds each. Sonicated pellet was resuspended in supernatant and saved as ' $C$. parvum whole lysate'. The concentration of the antigen fractions was determined by measurement of optical density using a Nanodrop instrument (ND-1000, NanoDrop Technologies).

\section{Pull-down of $C$. parvum antigens using $E$. coli Nissle}

A variety of modified pull-down studies utilizing the principles of ELISA, Western blot and immunofluorescence were applied to test the ability of anti-gp900 VHHs fused to EcN curli to bind their targets. All experiments used a nonspecific control $\mathrm{EcN}$ construct which expressed curli in fusion with a VHH targeting the green fluorescent protein (CsgA- $\alpha \mathrm{GFP})$.

For the ELISA, the goal was to pull-down C. parvum antigens by $\mathrm{EcN}$ immobilized to a plastic surface. Briefly, $100 \mu \mathrm{l}$ of induced overnight EcN cultures expressing CsgA- $\alpha g p 900-1$ and -2 were coated on 96well MaxiSorb plates at $2 \mathrm{x}$ concentration and incubated overnight at $4{ }^{\circ} \mathrm{C}$. The following day, plates were washed with TBS- $0.1 \%$ Tween and blocked with $4 \%$ milk-TBS- $0.1 \%$ Tween solution for $1 \mathrm{~h}$ at $37^{\circ} \mathrm{C}$. Plates were washed and C. parvum whole lysate was applied in 2-fold dilutions starting with $50 \mu \mathrm{g} / \mathrm{mL}$ concentration, and then incubated for $1 \mathrm{~h}$ at $37^{\circ} \mathrm{C}$. After washing, specifically bound C. parvum antigen was incubated with a second E-tagged detection VHH that binds to the same $C$. parvum antigen recognized by the EcN displayed $\mathrm{VHH}$, but to a non-competing epitope, at $1 \mu \mathrm{g} / \mathrm{mL}$ for $1 \mathrm{~h}$ at $37^{\circ} \mathrm{C}$.

Plates were then washed and incubated with an anti-E-tag HRP antibody (Bethyl Laboratories) at 1:10,000 for $1 \mathrm{~h}$ at $37^{\circ} \mathrm{C}$. Plates were washed a final time and OPD was added to each well for 20 
minutes. The reaction was stopped with $1 \mathrm{M} \mathrm{H} 2 \mathrm{SO} 4$ and absorbance was measured at $490 \mathrm{~nm}$ using a microplate reader.

For the Western blot, the goal was to quantify depletion of the target in the soluble whole lysate of $C$. parvum after incubation with $\mathrm{EcN}$ displaying an anti-gp900 $\mathrm{VHH}$ and removal from the solution by centrifugation. For target pull down, $50 \mu \mathrm{L}$ of the induced (for VHH display) and blocked EcN was suspended in PBS at $2 \mathrm{x}$ concentration and incubated with $30 \mu \mathrm{g}$ of $C$. parvum whole lysate for $1 \mathrm{~h}$ with rotation at room temperature. Samples were centrifuged $(5000 \times \mathrm{g}, 1 \mathrm{~min})$ and supernatant was collected for analysis. Fifteen $\mu \mathrm{L}$ supernatant aliquots of supernatant were diluted with 4xLDS buffer (Novagen) to achieve $1 \mathrm{x}$ concentration and denatured at $70^{\circ} \mathrm{C}$ for 10 minutes. Samples were loaded into the wells of 4 $12 \%$ Bis-Tris gel (Novex) and electrophoresed in 1x MOPS buffer at $100 \mathrm{~V}$ for 10 minutes and then at $200 \mathrm{~V}$ for 40 minutes. The gel was transferred on the nitrocellulose membrane using a wet transfer system (395 mA, 4h). Membranes were blocked with 4\% milk-TBS 0.1\% Tween for $1 \mathrm{~h}$ and washed with TBS-T before blotting with a second detection $\mathrm{VHH}$ (recognizing a non-competing epitope on the target) at 1 $\mu \mathrm{g} / \mathrm{ml}$ for $1 \mathrm{~h}$ with rotation. Membranes were then washed and incubated with a secondary anti-E-tag HRP antibody at 1:5,000 dilutions for $1 \mathrm{~h}$ with rotation. Western blots were developed using chemiluminescent substrate (GE Healthcare) and imaged using a ChemiDoc system (Bio-Rad). A densitometry analysis was performed using Image Lab software to report the percent of target band depletion as normalized to the loading control.

Immunofluorescent imaging was used to quantify $\mathrm{EcN}$ bacteria attached to $C$. parvum parasite and its trails immobilized on the surface. Pre-bleached $C$. parvum oocysts were suspended in $0.75 \%$ taurocholic acid and excysted in a $37^{\circ} \mathrm{C}$ water bath for 30 minutes to release sporozoites. Aliquots of excysted 10,000 oocysts were transferred onto poly-L-lysine slides (Chromaview) and incubated for another 30 minutes at $37^{\circ} \mathrm{C}$ under humidified conditions to allow for further excystation and gliding of sporozoites. Slides were then dried, fixed with $4 \%$ paraformaldehyde at room temperature (20 min) and washed with PBS. Such prepared parasites were then probed with $200 \mu \mathrm{L}$ of $2 \mathrm{x}$ EcN suspensions and incubated for $1 \mathrm{~h}$ at room 
temperature, after which they were washed with PBS to remove unbound $\mathrm{EcN}$. To detect EcN bound to the sporozoites and trails, slides were probed with anti-LPS Mab (ThermoFisher Scientific) at 1:200 dilution, followed by an anti-mouse IgG Alexa Fluor 568 antibody (Invitrogen) at 1:500 dilution, both incubated for $1 \mathrm{~h}$ at room temperature. Sporozoites were counterstained with an E-tagged VHH targeting gp900 at the apical complex and trails (CsgA- $\alpha \mathrm{gp} 900-2)$ at $1 \mu \mathrm{g} / \mathrm{mL}$ concentration, followed by an anti-Etag-FITC antibody (Bethyl Laboratories) at 1:100 dilution, both incubated for $1 \mathrm{~h}$ at room temperature. Lastly, slides were washed, dried, and mounted with antifade medium. Fluorescing sporozoites were imaged under epifluorescence (Nikon Eclipse Ti-E microscope, Nikon Instruments Inc.). The number of fluorescent foci was quantified using ImageJ 1.48v particle analyzer (U.S. National Institutes of Health, Bethesda, Maryland, USA).

\section{Statistical analysis}

All statistical analyses were performed using Prism 9.1.0 (GraphPad Software). Data are presented as mean \pm standard error of mean $(\mathrm{SEM})$, unless otherwise specified. Statistical significance was assessed using one-way or two-way analysis of variance (ANOVA), followed by Welsh's t-test, as described in figure legends.

\section{Acknowledgements}

This work was supported by the National Institutes of Health (1R01DK110770-01A1, R01DK113599-01) and the Bill and Melinda Gates Foundation (OPP1172434) (CBS/JML). Shenglan Hu received support from the Program of Study Abroad for Innovative Talents of Science and Technology by Guangdong Academy of Agricultural Science. 


\section{References}

1. Kotloff KL, Blackwelder WC, Nasrin D, Nataro JP, Farag TH, van Eijk A, et al. The Global Enteric Multicenter Study (GEMS) of Diarrheal Disease in Infants and Young Children in Developing Countries: Epidemiologic and Clinical Methods of the Case/Control Study. Clinical Infectious Diseases. 2012;55(suppl_4):S232-S45.

2. Kotloff KL, Nataro JP, Blackwelder WC, Nasrin D, Farag TH, Panchalingam S, et al. Burden and aetiology of diarrhoeal disease in infants and young children in developing countries (the Global Enteric Multicenter Study, GEMS): a prospective, case-control study. The Lancet. 2013;382(9888):209-22.

3. Nicolini G, Sperotto F, Esposito S. Combating the rise of antibiotic resistance in children. Minerva Pediatr. 2014;66(1):31-9.

4. Kotloff KL, Nasrin D, Blackwelder WC, Wu Y, Farag T, Panchalingham S, et al. The incidence, aetiology, and adverse clinical consequences of less severe diarrhoeal episodes among infants and children residing in low-income and middle-income countries: a 12-month case-control study as a followon to the Global Enteric Multicenter Study (GEMS). The Lancet Global Health. 2019;7(5):e568-e84.

5. Levine MM, Nasrin D, Acácio S, Bassat Q, Powell H, Tennant SM, et al. Diarrhoeal disease and subsequent risk of death in infants and children residing in low-income and middle-income countries: analysis of the GEMS case-control study and 12-month GEMS-1A follow-on study. The Lancet Global Health. 2020;8(2):e204-e14.

6. Fischer Walker CL, Perin J, Aryee MJ, Boschi-Pinto C, Black RE. Diarrhea incidence in low- and middle-income countries in 1990 and 2010: a systematic review. BMC Public Health. 2012;12(1):220. 7. Moon HW, Whipp SC, Argenzio RA, Levine MM, Giannella RA. Attaching and effacing activities of rabbit and human enteropathogenic Escherichia coli in pig and rabbit intestines. Infection and immunity. 1983;41(3):1340-51.

8. Kaper JB, Nataro JP, Mobley HLT. Pathogenic Escherichia coli. Nature Reviews Microbiology. 2004;2(2):123-40. 
9. Lai Y, Rosenshine I, Leong JM, Frankel G. Intimate host attachment: enteropathogenic and enterohaemorrhagic Escherichia coli. Cellular microbiology. 2013;15(11):1796-808.

10. Mallick EM, Garber JJ, Vanguri VK, Balasubramanian S, Blood T, Clark S, et al. The ability of an attaching and effacing pathogen to trigger localized actin assembly contributes to virulence by promoting mucosal attachment. Cellular microbiology. 2014;16(9):1405-24.

11. Gyles CL. Shiga toxin-producing Escherichia coli: An overview1. Journal of Animal Science. 2007;85(suppl_13):E45-E62.

12. Marder Mph EP, Griffin PM, Cieslak PR, Dunn J, Hurd S, Jervis R, et al. Preliminary Incidence and Trends of Infections with Pathogens Transmitted Commonly Through Food - Foodborne Diseases Active Surveillance Network, 10 U.S. Sites, 2006-2017. MMWR Morb Mortal Wkly Rep. 2018;67(11):324-8.

13. Fatima R, Aziz M. Enterohemorrhagic Escherichia Coli (EHEC). StatPearls [Internet]. 2020.

14. Schauer DB, Falkow S. Attaching and effacing locus of a Citrobacter freundii biotype that causes transmissible murine colonic hyperplasia. Infection and immunity. 1993;61(6):2486-92.

15. Mundy R, MacDonald TT, Dougan G, Frankel G, Wiles S. Citrobacter rodentium of mice and man. Cellular microbiology. 2005;7(12):1697-706.

16. Gaytán MO, Martínez-Santos VI, Soto E, González-Pedrajo B. Type Three Secretion System in Attaching and Effacing Pathogens. Front Cell Infect Microbiol. 2016;6:129-.

17. Maffey L, Vega CG, Parreño V, Garaicoechea L. Controlling Rotavirus-associated diarrhea:

Could single-domain antibody fragments make the difference? Revista Argentina de microbiologia. 2015;47(4):368-79.

18. Virdi V, Palaci J, Laukens B, Ryckaert S, Cox E, Vanderbeke E, et al. Yeast-secreted, dried and food-admixed monomeric IgA prevents gastrointestinal infection in a piglet model. Nature Biotechnology. 2019;37(5):527-30. 
19. Sheoran AS, Dmitriev IP, Kashentseva EA, Cohen O, Mukherjee J, Debatis M, et al. Adenovirus vector expressing Stx1/Stx2-neutralizing agent protects piglets infected with Escherichia coli O157:H7 against fatal systemic intoxication. Infection and immunity. 2015;83(1):286-91.

20. Barta ML, Shearer JP, Arizmendi O, Tremblay JM, Mehzabeen N, Zheng Q, et al. Single-domain antibodies pinpoint potential targets within Shigella invasion plasmid antigen D of the needle tip complex for inhibition of type III secretion. Journal of Biological Chemistry. 2017;292(40):16677-87.

21. Ruano-Gallego D, Yara DA, Di Ianni L, Frankel G, Schüller S, Fernández L. A nanobody targeting the translocated intimin receptor inhibits the attachment of enterohemorrhagic E. coli to human colonic mucosa. PLoS pathogens. 2019;15(8):e1008031.

22. Schmidt DJ, Beamer G, Tremblay JM, Steele JA, Kim HB, Wang Y, et al. A Tetraspecific VHHBased Neutralizing Antibody Modifies Disease Outcome in Three Animal Models of Clostridium difficile Infection. Clinical and vaccine immunology : CVI. 2016;23(9):774-84.

23. Vanmarsenille C, Díaz Del Olmo I, Elseviers J, Hassanzadeh Ghassabeh G, Moonens K, Vertommen D, et al. Nanobodies targeting conserved epitopes on the major outer membrane protein of Campylobacter as potential tools for control of Campylobacter colonization. Veterinary research. 2017;48(1):86.

24. Riazi A, Strong PC, Coleman R, Chen W, Hirama T, van Faassen H, et al. Pentavalent singledomain antibodies reduce Campylobacter jejuni motility and colonization in chickens. PloS one. 2013;8(12):e83928.

25. Tremblay JM, Mukherjee J, Leysath CE, Debatis M, Ofori K, Baldwin K, et al. A Single VHHBased Toxin-Neutralizing Agent and an Effector Antibody Protect Mice against Challenge with Shiga Toxins 1 and 2. Infection and immunity. 2013;81(12):4592.

26. Vega CG, Bok M, Vlasova AN, Chattha KS, Gómez-Sebastián S, Nuñez C, et al. Recombinant monovalent llama-derived antibody fragments $(\mathrm{VHH})$ to rotavirus VP6 protect neonatal gnotobiotic piglets against human rotavirus-induced diarrhea. PLoS pathogens. 2013;9(5):e1003334. 
27. Maffey L, Vega CG, Miño S, Garaicoechea L, Parreño V. Anti-VP6 VHH: An Experimental Treatment for Rotavirus A-Associated Disease. PloS one. 2016;11(9):e0162351.

28. Amcheslavsky A, Wallace AL, Ejemel M, Li Q, McMahon CT, Stoppato M, et al. Anti-CfaE nanobodies provide broad cross-protection against major pathogenic enterotoxigenic Escherichia coli strains, with implications for vaccine design. Scientific reports. 2021;11(1):2751.

29. Muyldermans S. Applications of Nanobodies. Annual review of animal biosciences. 2021;9:401-

21.

30. Muyldermans S. Nanobodies: natural single-domain antibodies. Annual review of biochemistry. 2013;82:775-97.

31. Gurbatri CR, Lia I, Vincent R, Coker C, Castro S, Treuting PM, et al. Engineered probiotics for local tumor delivery of checkpoint blockade nanobodies. Science Translational Medicine. 2020;12(530):eaax0876.

32. Chiabai MJ, Almeida JF, de Azevedo MGD, Fernandes SS, Pereira VB, de Castro RJA, et al. Mucosal delivery of Lactococcus lactis carrying an anti-TNF scFv expression vector ameliorates experimental colitis in mice. BMC biotechnology. 2019;19(1):38.

33. Afchangi A, Latifi T, Jalilvand S, Marashi SM, Shoja Z. Combined use of lactic-acid-producing bacteria as probiotics and rotavirus vaccine candidates expressing virus-specific proteins. Archives of virology. 2021;166(4):995-1006.

34. Ou B, Yang Y, Tham WL, Chen L, Guo J, Zhu G. Genetic engineering of probiotic Escherichia coli Nissle 1917 for clinical application. Applied Microbiology and Biotechnology. 2016;100(20):8693-9. 35. Kurtz CB, Millet YA, Puurunen MK, Perreault M, Charbonneau MR, Isabella VM, et al. An engineered E. coli Nissle improves hyperammonemia and survival in mice and shows dose-dependent exposure in healthy humans. Science Translational Medicine. 2019;11(475):eaau7975.

36. Kruis W, Frič P, Pokrotnieks J, Lukáš M, Fixa B, Kaščák M, et al. Maintaining remission of ulcerative colitis with the probiotic Escherichia coli Nissle 1917 is as effective as with standard mesalazine. Gut. 2004;53(11):1617. 
37. Altenhoefer A, Oswald S, Sonnenborn U, Enders C, Schulze J, Hacker J, et al. The probiotic Escherichia coli strain Nissle 1917 interferes with invasion of human intestinal epithelial cells by different enteroinvasive bacterial pathogens. FEMS Immunology \& Medical Microbiology. 2004;40(3):223-9.

38. Hancock V, Dahl M, Klemm P. Probiotic Escherichia coli strain Nissle 1917 outcompetes intestinalpathogens during biofilm formation. Journal of Medical Microbiology. 2010;59(4):392-9.

39. Blum-Oehler G, Oswald S, Eiteljörge K, Sonnenborn U, Schulze J, Kruis W, et al. Development of strain-specific PCR reactions for the detection of the probiotic Escherichia coli strain Nissle 1917 in fecal samples. Research in Microbiology. 2003;154(1):59-66.

40. Kurtz C, Denney WS, Blankstein L, Guilmain SE, Machinani S, Kotula J, et al. Translational Development of Microbiome-Based Therapeutics: Kinetics of E. coli Nissle and Engineered Strains in Humans and Nonhuman Primates. Clinical and translational science. 2018;11(2):200-7.

41. Gibbs WW. Nanobodies. Scientific American. 2005;293(2):78-83.

42. Piñero-Lambea C, Bodelón G, Fernández-Periáñez R, Cuesta AM, Álvarez-Vallina L, Fernández LÁ. Programming Controlled Adhesion of E. coli to Target Surfaces, Cells, and Tumors with Synthetic Adhesins. ACS Synthetic Biology. 2015;4(4):463-73.

43. Praveschotinunt P, Duraj-Thatte AM, Gelfat I, Bahl F, Chou DB, Joshi NS. Engineered E. coli Nissle 1917 for the delivery of matrix-tethered therapeutic domains to the gut. Nature Communications. 2019;10(1):5580.

44. Nguyen PQ, Botyanszki Z, Tay PKR, Joshi NS. Programmable biofilm-based materials from engineered curli nanofibres. Nature Communications. 2014;5(1):4945.

45. Connor EF, Lees I, Maclean D. Polymers as drugs-Advances in therapeutic applications of polymer binding agents. Journal of Polymer Science Part A: Polymer Chemistry. 2017;55(18):3146-57.

46. Liu S, Maheshwari R, Kiick KL. Polymer-Based Therapeutics. Macromolecules. 2009;42(1):313.

47. Pardon E, Laeremans T, Triest S, Rasmussen SG, Wohlkönig A, Ruf A, et al. A general protocol for the generation of Nanobodies for structural biology. Nature protocols. 2014;9(3):674-93. 
48. Luo Y, Frey EA, Pfuetzner RA, Creagh AL, Knoechel DG, Haynes CA, et al. Crystal structure of enteropathogenic Escherichia coli intimin-receptor complex. Nature. 2000;405(6790):1073-7.

49. Weikum J, Kulakova A, Tesei G, Yoshimoto S, Jægerum LV, Schütz M, et al. The extracellular juncture domains in the intimin passenger adopt a constitutively extended conformation inducing restraints to its sphere of action. Scientific reports. 2020;10(1):21249.

50. Liu H, Magoun L, Luperchio S, Schauer DB, Leong JM. The Tir-binding region of enterohaemorrhagic Escherichia coli intimin is sufficient to trigger actin condensation after bacterialinduced host cell signalling. Molecular microbiology. 1999;34(1):67-81.

51. Girón JA, Torres AG, Freer E, Kaper JB. The flagella of enteropathogenic Escherichia coli mediate adherence to epithelial cells. Molecular microbiology. 2002;44(2):361-79.

52. Praveschotinunt P, Dorval Courchesne N-M, den Hartog I, Lu C, Kim JJ, Nguyen PQ, et al. Tracking of Engineered Bacteria In Vivo Using Nonstandard Amino Acid Incorporation. ACS Synthetic Biology. 2018;7(6):1640-50.

53. Zhou Y, Smith DR, Hufnagel DA, Chapman MR. Experimental manipulation of the microbial functional amyloid called curli. Methods Mol Biol. 2013;966:53-75.

54. Rothbauer U, Zolghadr K, Tillib S, Nowak D, Schermelleh L, Gahl A, et al. Targeting and tracing antigens in live cells with fluorescent nanobodies. Nature Methods. 2006;3(11):887-9.

55. Hussack G, Arbabi-Ghahroudi M, van Faassen H, Songer JG, Ng KKS, MacKenzie R, et al. Neutralization of Clostridium difficile Toxin A with Single-domain Antibodies Targeting the Cell Receptor Binding Domain. Journal of Biological Chemistry. 2011;286(11):8961-76.

56. Jaskiewicz JJ, Tremblay JM, Tzipori S, Shoemaker CB. Identification and characterization of a new $34 \mathrm{kDa}$ MORN motif-containing sporozoite surface-exposed protein, $\mathrm{Cp}-\mathrm{P} 34$, unique to Cryptosporidium. International Journal for Parasitology. 2021.

57. Melton-Celsa AR. Shiga Toxin (Stx) Classification, Structure, and Function. Microbiol Spectr. 2014;2(4):10.1128/microbiolspec.EHEC-0024-2013-. 
58. Namba K, Yamashita I, Vonderviszt F. Structure of the core and central channel of bacterial flagella. Nature. 1989;342(6250):648-54.

59. Bajunaid W, Haidar-Ahmad N, Kottarampatel AH, Ourida Manigat F, Silué N, F. Tchagang C, et al. The T3SS of Shigella: Expression, Structure, Function, and Role in Vacuole Escape. Microorganisms. $2020 ; 8(12)$.

60. Espina M, Olive AJ, Kenjale R, Moore DS, Ausar SF, Kaminski RW, et al. IpaD Localizes to the Tip of the Type III Secretion System Needle of Shigella flexneri. Infection and immunity. 2006;74(8):4391.

61. Dickenson NE, Zhang L, Epler CR, Adam PR, Picking WL, Picking WD. Conformational Changes in IpaD from Shigella flexneri upon Binding Bile Salts Provide Insight into the Second Step of Type III Secretion. Biochemistry. 2011;50(2):172-80.

62. Picking WL, Nishioka H, Hearn PD, Baxter MA, Harrington AT, Blocker A, et al. IpaD of Shigella flexneri Is Independently Required for Regulation of Ipa Protein Secretion and Efficient Insertion of IpaB and IpaC into Host Membranes. Infection and immunity. 2005;73(3):1432.

63. Blocker A, Gounon P, Larquet E, Niebuhr K, Cabiaux V, Parsot C, et al. The Tripartite Type III Secreton of Shigella flexneri Inserts Ipab and Ipac into Host Membranes. Journal of Cell Biology. 1999;147(3):683-93.

64. Cryptosporidiosis Summary Report - National Notifiable Diseases Surveillance System, United States, 2018 [Internet]. Atlanta (GA): Centers for Disease Control and Prevention; 2019 [cited 2021 May 13]. Available from: https://www.cdc.gov/healthywater/surveillance/cryptosporidium/cryptosporidium2018.html.

65. Kiros H, Nibret E, Munshea A, Kerisew B, Adal M. Prevalence of intestinal protozoan infections among individuals living with HIV/AIDS at Felegehiwot Referral Hospital, Bahir Dar, Ethiopia. International Journal of Infectious Diseases. 2015;35:80-6.

66. Love MS, McNamara CW. Phenotypic screening techniques for Cryptosporidium drug discovery. Expert Opinion on Drug Discovery. 2021;16(1):59-74. 
67. Barnes DA, Bonnin A, Huang J-X, Gousset L, Wu J, Gut J, et al. A novel multi-domain mucinlike glycoprotein of Cryptosporidium parvum mediates invasion1Note: Nucleotide sequence data reported in this paper are available in the EMBL, GenBank ${ }^{\mathrm{TM}}$ and DDJB databases under the accession number AF068065.1,2A portion of the amino acid sequence of GP900 was presented at the 47th annual meeting of the Society of Protozoologists and 3rd Workshop on opportunistic Protozoan Pathogens in Cleveland, Ohio, June 1994.2. Molecular and Biochemical Parasitology. 1998;96(1):93-110.

68. Kitov PI, Sadowska JM, Mulvey G, Armstrong GD, Ling H, Pannu NS, et al. Shiga-like toxins are neutralized by tailored multivalent carbohydrate ligands. Nature. 2000;403(6770):669-72.

69. Mulvey GL, Marcato P, Kitov PI, Sadowska J, Bundle DR, Armstrong GD. Assessment in Mice of the Therapeutic Potential of Tailored, Multivalent Shiga Toxin Carbohydrate Ligands. The Journal of infectious diseases. 2003;187(4):640-9.

70. Moayeri M, Leysath CE, Tremblay JM, Vrentas C, Crown D, Leppla SH, et al. A Heterodimer of a VHH (Variable Domains of Camelid Heavy Chain-only) Antibody That Inhibits Anthrax Toxin Cell Binding Linked to a VHH Antibody That Blocks Oligomer Formation Is Highly Protective in an Anthrax Spore Challenge Model*. Journal of Biological Chemistry. 2015;290(10):6584-95.

71. Dey P, Bergmann T, Cuellar-Camacho JL, Ehrmann S, Chowdhury MS, Zhang M, et al. Multivalent Flexible Nanogels Exhibit Broad-Spectrum Antiviral Activity by Blocking Virus Entry. ACS Nano. 2018;12(7):6429-42.

72. Duraj-Thatte AM, Courchesne N-MD, Praveschotinunt P, Rutledge J, Lee Y, Karp JM, et al. Genetically Programmable Self-Regenerating Bacterial Hydrogels. Advanced Materials. 2019;31(40):1901826.

73. Efficacy and Safety of SYNB1618 in Adult Patients With Phenylketonuria. 2020 Sep 1 [last updated 2021 May 12; cited 2021 May 13]. Bethesda (MD): U.S. National Library of Medicine. Available from: https://clinicaltrials.gov/ct2/show/NCT04534842. Clinicaltrials.gov identifier: NCT04534842. 
74. Safety and Tolerability of SYNB1618 in Healthy Adult Volunteers and Adult Subjects With Phenylketonuria. 2018 May 4 [last updated 2021 May 13; cited 2021 May 13]. Bethesda (MD): U.S. National Library of Medicine. Available from: https://clinicaltrials.gov/ct2/show/NCT03516487. Clinicaltrials.gov identifier: NCT03516487.

75. Safety and Tolerability of SYNB1891 Injection Alone or in Combination With Atezolizumab in Adult Subjects. 2019 Nov 18 [last updated 2021 May 12; cited 2021 May 13]. Bethesda (MD): U.S. National Library of Medicine. Available from: https://clinicaltrials.gov/ct2/show/NCT04167137. Clinicaltrials.gov identifier: NCT04167137.

76. Safety and Tolerability of SYNB8802 in Healthy Adult Volunteers and Adult Subjects With Enteric Hyperoxaluria. 2020 Nov 16 [last updated 2021 May 12; cited 2021 May 13]. Bethesda (MD): U.S. National Library of Medicine. Available from: https://clinicaltrials.gov/ct2/show/NCT04629170. Clinicaltrials.gov identifier: NCT04629170.

77. Maltby R, Leatham-Jensen MP, Gibson T, Cohen PS, Conway T. Nutritional basis for colonization resistance by human commensal Escherichia coli strains HS and Nissle 1917 against E. coli O157:H7 in the mouse intestine. PloS one. 2013;8(1):e53957.

78. Jacobi CA, Malfertheiner P. Escherichia coli Nissle 1917 (Mutaflor): New Insights into an Old Probiotic Bacterium. Digestive Diseases. 2011;29(6):600-7.

79. Van Gerven N, Klein RD, Hultgren SJ, Remaut H. Bacterial Amyloid Formation: Structural Insights into Curli Biogensis. Trends in Microbiology. 2015;23(11):693-706.

80. Van Gerven N, Goyal P, Vandenbussche G, De Kerpel M, Jonckheere W, De Greve H, et al. Secretion and functional display of fusion proteins through the curli biogenesis pathway. Molecular microbiology. 2014;91(5):1022-35.

81. Pu J, Liu Y, Zhang J, An B, Li Y, Wang X, et al. Virus Disinfection from Environmental Water Sources Using Living Engineered Biofilm Materials. Advanced Science. 2020;7(14):1903558. 
82. Okhuysen PC, Rich SM, Chappell CL, Grimes KA, Widmer G, Feng X, et al. Infectivity of a Cryptosporidium parvum Isolate of Cervine Origin for Healthy Adults and Interferon- $\gamma$ Knockout Mice. The Journal of infectious diseases. 2002;185(9):1320-5.

83. Widmer G, Tzipori S, Fichtenbaum CJ, Griffiths JK. Genotypic and phenotypic characterization of Cryptosporidium parvum isolates from people with AIDS. The Journal of infectious diseases. 1998;178(3):834-40.

84. Tacket CO, Maneval DR, Levine MM. Purification, morphology, and genetics of a new fimbrial putative colonization factor of enterotoxigenic Escherichia coli O159:H4. Infection and immunity. 1987;55(5):1063.

85. Vrentas CE, Moayeri M, Keefer AB, Greaney AJ, Tremblay J, O'Mard D, et al. A Diverse Set of Single-domain Antibodies (VHHs) against the Anthrax Toxin Lethal and Edema Factors Provides a Basis for Construction of a Bispecific Agent That Protects against Anthrax Infection. Journal of Biological Chemistry. 2016;291(41):21596-606.

86. Tremblay JM, Kuo CL, Abeijon C, Sepulveda J, Oyler G, Hu X, et al. Camelid single domain antibodies (VHHs) as neuronal cell intrabody binding agents and inhibitors of Clostridium botulinum neurotoxin (BoNT) proteases. Toxicon : official journal of the International Society on Toxinology. 2010;56(6):990-8.

87. Campellone KG, Giese N, Tipper OJ, Leong JM. A tyrosine-phosphorylated 12-amino-acid sequence of enteropathogenic Escherichia coli Tir binds the host adaptor protein Nck and is required for Nck localization to actin pedestals. Molecular microbiology. 2002;43(5):1227-41.

88. Kan A, Birnbaum DP, Praveschotinunt P, Joshi NS. Congo Red Fluorescence for Rapid In Situ Characterization of Synthetic Curli Systems. Applied and Environmental Microbiology. 2019;85(13):e00434-19.

89. Gibson DG, Young L, Chuang R-Y, Venter JC, Hutchison CA, Smith HO. Enzymatic assembly of DNA molecules up to several hundred kilobases. Nature Methods. 2009;6(5):343-5. 
90. Vertzoni M, Diakidou A, Chatzilias M, Söderlind E, Abrahamsson B, Dressman JB, et al.

Biorelevant media to simulate fluids in the ascending colon of humans and their usefulness in predicting intracolonic drug solubility. Pharmaceutical research. 2010;27(10):2187-96.

91. Mukherjee J, Tremblay JM, Leysath CE, Ofori K, Baldwin K, Feng X, et al. A Novel Strategy for Development of Recombinant Antitoxin Therapeutics Tested in a Mouse Botulism Model. PloS one. 2012;7(1):e29941.

92. Yang Z, Schmidt D, Liu W, Li S, Shi L, Sheng J, et al. A Novel Multivalent, Single-Domain Antibody Targeting TcdA and TcdB Prevents Fulminant Clostridium difficile Infection in Mice. The Journal of infectious diseases. 2014;210(6):964-72.

93. Casadaban MJ, Cohen SN. Analysis of gene control signals by DNA fusion and cloning in Escherichia coli. Journal of Molecular Biology. 1980;138(2):179-207.

94. Mills JA. Molecular characterization of a noninvasive opaque colonial variant of Shigella flexneri. 1992.

95. Iguchi A, Thomson NR, Ogura Y, Saunders D, Ooka T, Henderson IR, et al. Complete Genome Sequence and Comparative Genome Analysis of Enteropathogenic Escherichia coli O127:H6 Strain E2348/69. Journal of Bacteriology. 2009;191(1):347.

96. Brien AD, LaVeck GD. Purification and characterization of a Shigella dysenteriae 1-like toxin produced by Escherichia coli. Infection and immunity. 1983;40(2):675.

97. Camguilhem R, Milon A. Biotypes and O serogroups of Escherichia coli involved in intestinal infections of weaned rabbits: clues to diagnosis of pathogenic strains. Journal of Clinical Microbiology. 1989;27(4):743.

98. García A, Marini RP, Feng Y, Vitsky A, Knox KA, Taylor NS, et al. A Naturally Occurring Rabbit Model of Enterohemorrhagic Escherichia coli-Induced Disease. The Journal of infectious diseases. 2002;186(11):1682-6. 
99. Mallick EM, McBee ME, Vanguri VK, Melton-Celsa AR, Schlieper K, Karalius BJ, et al. A novel murine infection model for Shiga toxin-producing Escherichia coli. The Journal of Clinical Investigation. 2012;122(11):4012-24.

100. Yu J, Kaper JB. Cloning and characterization of the eae gene of enterohaemorrhagic Escherichia coli O157:H7. Molecular microbiology. 1992;6(3):411-7.

101. Burland V, Shao Y, Perna NT, Plunkett G, Blattner FR, Sofia HJ. The complete DNA sequence and analysis of the large virulence plasmid of Escherichia coli O157:H7. Nucleic Acids Research. 1998;26(18):4196-204.

102. Liu H, Radhakrishnan P, Magoun L, Prabu M, Campellone KG, Savage P, et al. Point mutants of EHEC intimin that diminish Tir recognition and actin pedestal formation highlight a putative Tir binding pocket. Molecular microbiology. 2002;45(6):1557-73.

103. Yanisch-Perron C, Vieira J, Messing J. Improved M13 phage cloning vectors and host strains: nucleotide sequences of the M13mp18 and pUC19 vectors. Gene. 1985;33(1):103-19. 